\title{
Morphology of the ring current derived from magnetic field observations
}

\author{
G. Le ${ }^{1}$, C. T. Russell ${ }^{2}$, and K. Takahashi ${ }^{3}$ \\ ${ }^{1}$ Laboratory for Extraterrestrial Physics, NASA Goddard Space Flight Center, Greenbelt, MD 20771, USA \\ ${ }^{2}$ Institute of Geophysics and Planetary Physics, University of California, Los Angeles, CA 90095-1567, USA \\ ${ }^{3}$ Applied Physics Laboratory, Johns Hopkins University, Laurel, MD 20723, USA
}

Received: 25 April 2003 - Revised: 5 August 2003 - Accepted: 4 September 2003 - Published: 2 April 2004

\begin{abstract}
Our examination of the 20 years of magnetospheric magnetic field data from ISEE, AMPTE/CCE and Polar missions has allowed us to quantify how the ring current flows and closes in the magnetosphere at a variety of disturbance levels. Using intercalibrated magnetic field data from the three spacecraft, we are able to construct the statistical magnetic field maps and derive 3-dimensional current density by the simple device of taking the curl of the statistically determined magnetic field. The results show that there are two ring currents, an inner one that flows eastward at $\sim 3 R_{E}$ and a main westward ring current at $\sim 4-7 R_{E}$ for all levels of geomagnetic disturbances. In general, the insitu observations show that the ring current varies as the $D_{s t}$ index decreases, as we would expect it to change. An unexpected result is how asymmetric it is in local time. Some current clearly circles the magnetosphere but much of the energetic plasma stays in the night hemisphere. These energetic particles appear not to be able to readily convect into the dayside magnetosphere. During quiet times, the symmetric and partial ring currents are similar in strength $(\sim 0.5 \mathrm{MA})$ and the peak of the westward ring current is close to local midnight. It is the partial ring current that exhibits most drastic intensification as the level of disturbances increases. Under the condition of moderate magnetic storms, the total partial ring current reaches $\sim 3 \mathrm{MA}$, whereas the total symmetric ring current is $\sim 1 \mathrm{MA}$. Thus, the partial ring current contributes dominantly to the decrease in the $D_{s t}$ index. As the ring current strengthens the peak of the partial ring current shifts duskward to the pre-midnight sector. The partial ring current is closed by a meridional current system through the ionosphere, mainly the field-aligned current, which maximizes at local times near the dawn and dusk. The closure currents flow in the sense of region-2 field-aligned currents, downward into the ionosphere near the dusk and upward out of the ionosphere near the dawn.
\end{abstract}

Key words. Magnetospheric physics (current systems; storms and substorms; magnetospheric configuration and dynamics)

Correspondence to: G. Le

(guan.le@nasa.gov)

\section{Introduction}

The ring current is one of the oldest concepts in magnetospheric physics, yet still one of the most poorly understood. The proposal of a ring of current encircling the magnetosphere was first introduced by Störmer (1911) and given additional support by Schmidt (1917). A ring current was later used in the model of the geomagnetic storm presented in a series of papers by Chapman and Ferraro (1931) to (1941). In this model an enhanced stream of solar wind plasma compresses the Earth's magnetic field. Thereafter some of the energetic plasma from that stream enters the Earth's magnetosphere and inflates it. The last of these papers (Chapman and Ferraro, 1941) contains a detailed treatment of the ring current that formed during the storm's main phase. The modern concept of a radiation belt of bouncing and drifting protons and electrons trapped within the magnetosphere and producing the ring current was proposed by Singer (1957) and confirmed with the discovery of the radiation belts by both US and Soviet teams in 1959 (Van Allen and Frank, 1959b; Van Allen et al., 1959a; Vernov et al., 1969). Shortly thereafter Dessler and Parker (1959) and Sckopke (1966) showed that the magnetic field depression at the center of the Earth was proportional to the energy content of the particles trapped in the magnetic field. The depression on the surface of the Earth, the equatorial average value of which we term the $D_{s t}$ index, is additionally enhanced by currents within the Earth that exclude the field of the newly-formed ring current from the Earth's interior.

At one time it was believed that a magnetic storm and hence, the ring current was built up from a series of small disturbances called substorms (Akasofu, 1968; Kamide, 1979). However, storms occur generally when the interplanetary magnetic field (IMF) is strong and steady and not in intervals of fluctuating IMF (Russell et al., 1974; Russell et al., 2000). Using what was understood about the control of the reconnection by the IMF, Burton et al. (1975) demonstrated that the ring current could be predicted from solar wind parameters with an extremely simple prescription. Energy is injected into the ring current at a rate proportional to the amount of convected southward IMF (i.e. the dawn-dusk interplanetary 


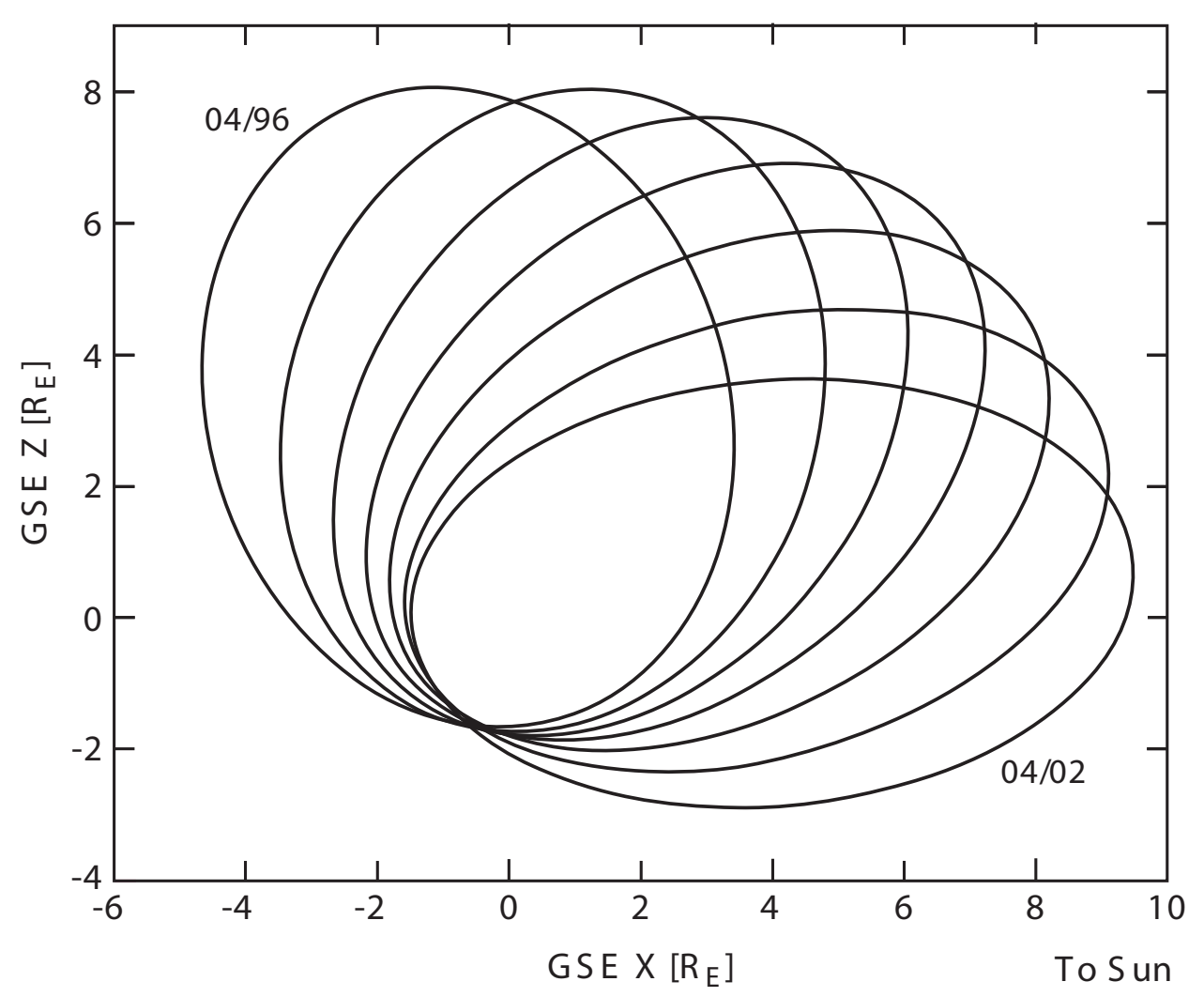

Annual Precession of Polar Orbit

Fig. 1. The evaluation of the Polar orbit from April 1996 to April 2002. The orbit is shown in the solar ecliptic (GSE) $X-Z$ plane for the orbit that was closest in this plane close to the spring equinox. The tilt of the dipole axis relative to the rotational axis of the Earth and the tilt of the rotation axis to the ecliptic pole will cause the coverage to spread over a greater area in any magnetically-oriented coordinate system, such as the solar magnetic (SM) system used in this paper.

electric field) and decays at a steady rate. The solar wind dynamic pressure controls the currents on the magnetopause that add to the disturbance seen at ground level. Many studies of this process have been carried out since that time, sometimes producing complex relations, but none have altered the basic formula of reconnection controlled injection, and magnetospherically controlled decay with a superimposed contribution from the magnetopause currents. Moreover, the energy-field depression relation of Dessler-Parker-Sckopke has been confirmed by Hamilton et al. (1988) with an important contribution by Feldstein (1992).

In some senses we now have a very good understanding of the ultimate source of the energy of the ring current. Nevertheless, there still are many aspects of the ring current for which our understanding is poor. How does the energy of the solar wind result in the acceleration of the ionospheric particles that are found in the ring current? Where does the ring current flow? Is it symmetric? Is it concentrated at the equator? How does it couple to field-aligned currents? What is the closure of the partial ring current?

For over twenty years with the International Sun-Earth Explorer (ISEE), Active Magnetospheric Particle Tracer Ex-
plorers/Charge Composition Explorer (CCE), and now Polar we have been measuring the Earth's magnetic field in the region in which the ring current is flowing. We have amassed a data set that amply covers the volume of the magnetosphere over a large range of geomagnetic conditions. We now can make important headway in characterizing the morphology of the ring current by the simple device of taking the curl of the statistically determined magnetic field. In the sections below we report on our analysis.

\section{Data set}

In this paper we use in-situ magnetic field data in the inner magnetosphere to construct a 3-D map of the average magnetic field and derive the spatial distribution of the ring current density in the inner magnetosphere. The data used are the vector magnetic field measurements of a one-minute average combined from three spacecraft, including the first 5 years of the Polar mission (Russell et al., 1995), the entire 5 years of the AMPTE/CCE mission (Potemra et al., 1985), and the entire 10 years of the ISEE mission (Russell, 1978). Table 1 lists some information about the three missions. The 
Table 1. Data Set Information.

\begin{tabular}{cccc}
\hline Mission & Polar & AMPTE/CCE & ISEE \\
\hline Time Coverage & 16 March 1996-31 December 2000 & 21 August 1984-1 September 1989 & 22 October 1977-26 September 1987 \\
Launch Date & 24 February 1996 & 16 August 1984 & 22 October 1977 \\
Status & Operational & Terminated 14 July 1989 & Terminated 26 September 1987 \\
Apogee & $9 R_{E}$ & $8.8 R_{E}$ & $23 R_{E}$ \\
Perigee & $1.8 R_{E}$ & $1.17 R_{E}$ & $1.04 R_{E}$ \\
Inclination & $86^{\circ}$ & $4.8^{\circ}$ & $28.76^{\circ}$ \\
Period & $\sim 18 \mathrm{~h}$ & $\sim 16 \mathrm{~h}$ & $\sim 57 \mathrm{~h}$ \\
\hline
\end{tabular}

values listed in Table 1 are quite representative of the orbits of ISEE and CCE over their entire mission, but not so representative for Polar because of the rapid precession of its line of apsides. Thus, we display in Fig. 1 the evolution of the Polar orbit to show how in the first five years most of the Northern Hemisphere was covered, as well as some of the south. The combined data sets from the three missions provide an extensive coverage of the equatorial inner magnetosphere from 2 to $8 R_{E}$ in all local time sectors and over a wide range of the $D_{s t}$ index. They are ideal for a quantitative study of the ring current.

Before combining the data from the three missions into a single data set, we first intercalibrate the scale factors of the magnetometers on the three spacecraft. The scale factor converts the magnetic field measurements from the engineering unit (counts) into the physical unit (nT). It introduces errors mainly in the high field region, if it is not accurate. For example, an error of $0.1 \%$ in the scale factor will cause a $8 \mathrm{nT}$ error in a region with a $8000 \mathrm{nT}$ field, a typical value at $1 R_{E}$ altitude. To intercalibrate the scale factors of the magnetometers from the three missions, we use the Polar magnetic field data as reference and compare the ISEE and CCE magnetic field strength to the Polar magnetic field strength at $1 R_{E}$ altitudes in the equatorial plane. The correction factors for ISEE and CCE are determined by forcing the observed magnetic field strengths to agree with each other statistically. The results show that the scale factor needs to be decreased by $0.365 \%$ for the ISEE magnetometer and increased by $0.397 \%$ for the CCE magnetometer. The intercalibration of the scale factors significantly improves the quality of the data set in the high field region $\left(\mathrm{L}<4 R_{E}\right)$. We note that the Polar magnetometer has been calibrated against the terrestrial field at perigee on an orbit-by-orbit basis for the entire mission. ISEE and CCE, with fewer low altitude data, were not calibrated. Thus, it is quite reasonable to use the Polar data as the accurate reference.

\section{Data binning}

The next step is to sort the data into several ranges based on the ring current strength. It is well known that the $D_{s t}$ index includes contributions from both the ring current and the magnetopause current. The magnetopause current responds to the solar wind dynamic pressure $\left(\mathrm{P}_{\mathrm{sw}}\right)$ nearly instantaneously. Its contribution to the $D_{s t}$ index is proportional to the square root of the solar wind dynamic pressure, or $13.5\left(\mathrm{P}_{\mathrm{sw}}\right)^{1 / 2}$ in $\mathrm{nT}$, on average (Russell et al., 1994a, b), where $\mathrm{P}_{\mathrm{sw}}$ is in $\mathrm{nPa}$. Thus, the effect of the magnetopause current can be readily removed from the $D_{s t}$ index based on $\mathrm{P}_{\mathrm{sw}}$ data. The corrected index $D_{s t} *$ reflects the true ring current strength. After the correction, the $D_{s t} *$ index is almost always negative due to the continuous presence of a quiet time ring current. On a typical quiet day, the ring current creates a magnetic field of $\sim-20 \mathrm{nT}$ on the ground (Araki et al., 1993; Le and Russell, 1998).

The in-situ magnetic field data in this study are thus sorted based on $D_{s t}{ }^{*}$, the corrected index. We use the hourly solar wind proton density and bulk velocity data from near-Earth heliospheric data set (OMNI) available at the OMNIweb, to calculate the hourly solar wind dynamic pressure $\mathrm{P}_{\mathrm{sw}}$, assuming $4 \%$ helium content. The corrected index of $D_{s t}$ * is calculated by subtracting $13.5\left(\mathrm{P}_{\mathrm{sw}}\right)^{1 / 2}$ from the hourly $D_{s t}$ index. Then, we tag each one-minute average magnetic field data point with the nearest hourly $D_{s t} *$ index, and sort the data based on the $D_{s t} *$ index. The vast majority of the data points $(96 \%)$ fall into the $D_{s t} *$ range from $-20 \mathrm{nT}$ to $-100 \mathrm{nT}$. Thus, we group these data into four $\sim-20 \mathrm{nT} D_{s t} *$ ranges.

In the inner magnetosphere, the best coordinate system for the ring current study is the solar magnetic coordinates (SM), where the $Z$-axis is parallel to the north magnetic pole and the $Y$-axis is perpendicular to the Earth-Sun line towards dusk. In this study, all the magnetic field data points, as well as the corresponding spacecraft positions, are rotated into the SM coordinates initially. We then detrend the data by removing the internal magnetic field due to the Earth's core, using the International Geomagnetic Reference Field (IGRF) model. The resulting residuals $\left(\delta \mathrm{B}_{\mathrm{x}}, \delta \mathrm{B}_{\mathrm{y}}, \delta \mathrm{B}_{\mathrm{z}}\right)$ are the perturbation magnetic field caused by external magnetospheric current systems. We further transform the data point into the SM cylindrical coordinates $\left(\delta \mathrm{B}_{\rho}, \delta \mathrm{B}_{\varphi}, \delta \mathrm{B}_{\mathrm{Z}}\right)$, where $\delta \mathrm{B}_{\rho}$ is the component perpendicular to the magnetic axis (or the $Z$ axis) in the local magnetic meridian plane, and $\delta \mathrm{B}_{\varphi}$ is the azimuthal component perpendicular to the meridian plane. For each data point, the corresponding spacecraft position 


\section{Data Coverage for MLT $=0000$ \\ $-40 \mathrm{nT}>$ Dst $^{*}>-60 \mathrm{nT}$}

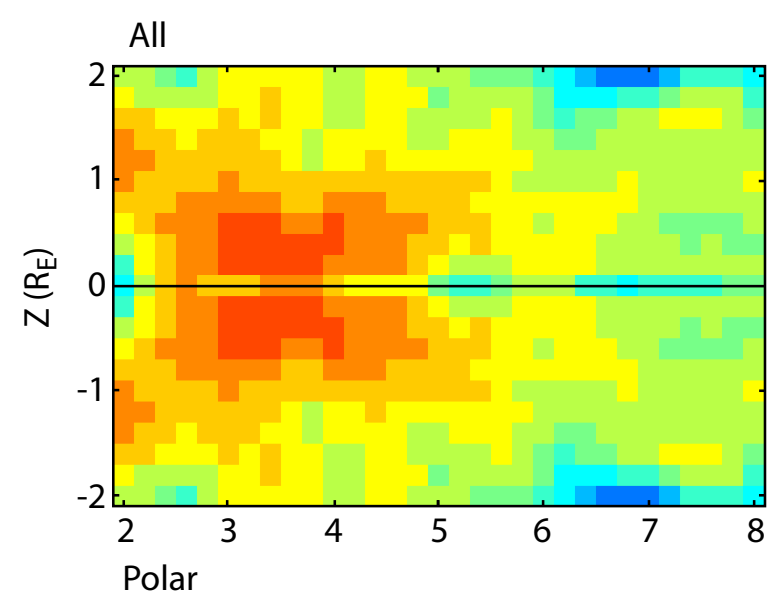

AMPTE/CCE
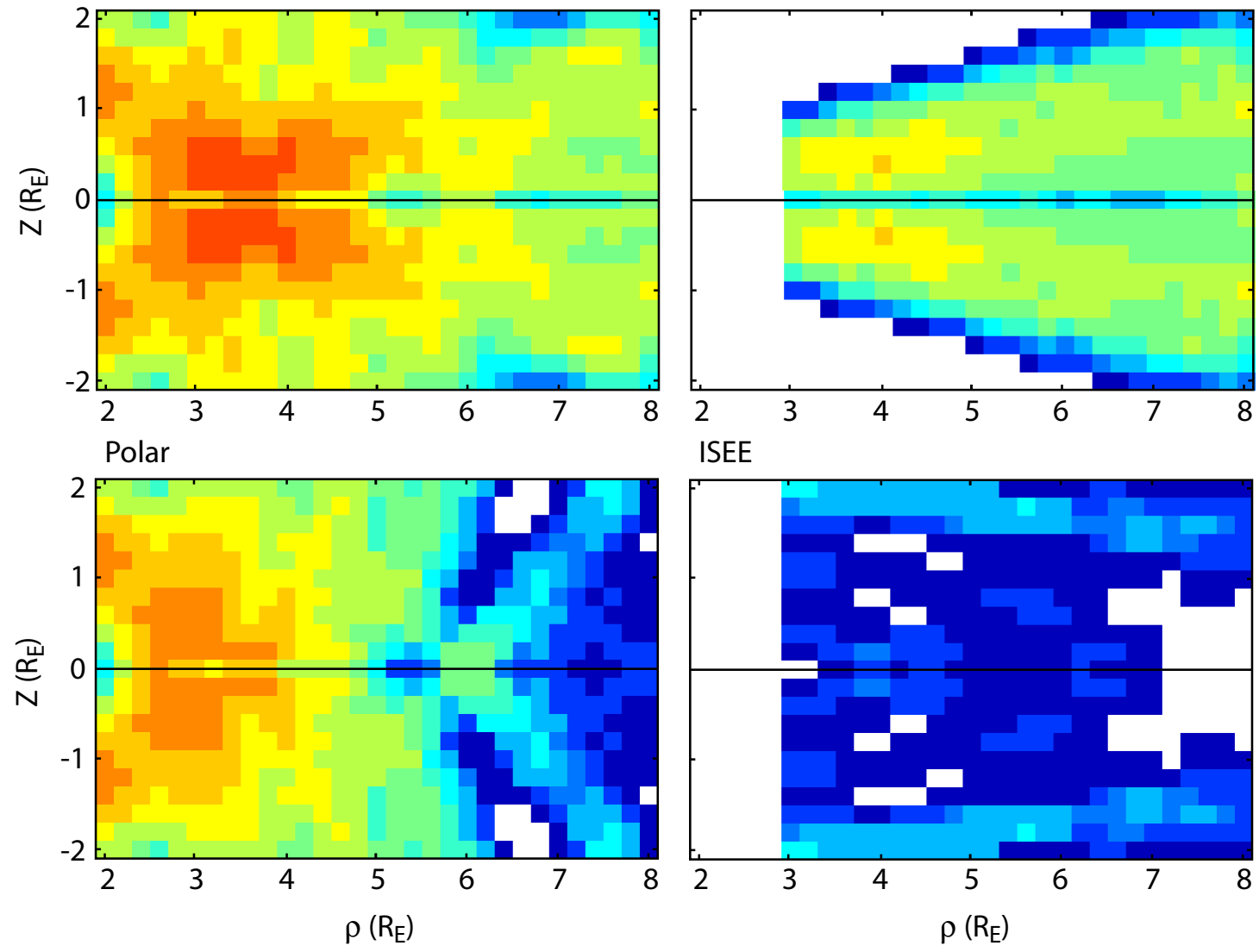

ISEE

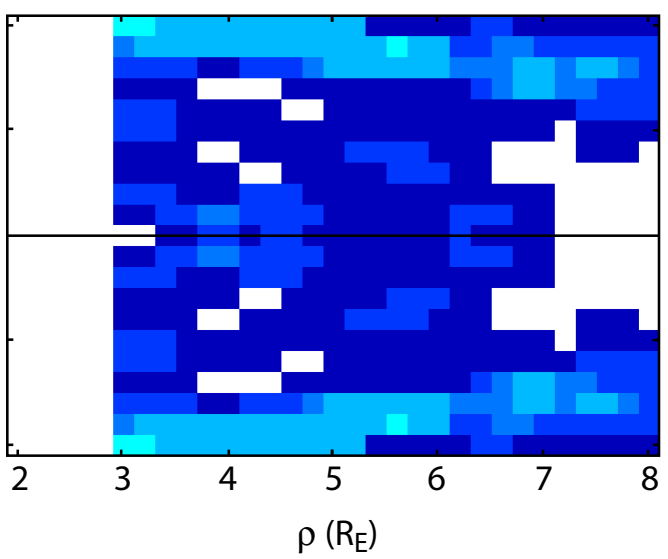

Number of Independent Data Points

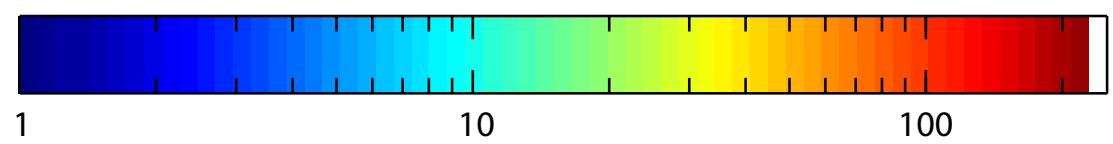

Fig. 2. Data coverage in the midnight plane for $-40 \mathrm{nT}>D_{s t} *>-60 \mathrm{nT}$ for all data sets and for Polar, ISEE and CCE separately.

tag is represented by $(\rho, \varphi, \mathrm{Z})$ in the cylindrical coordinates, where $\rho$ is the distance from the magnetic axis (or the $Z$ axis), $\varphi$ is the azimuth angle, and $\mathrm{Z}$ is the distance from the magnetic equator. The magnetic local time (MLT) can be calculated from the azimuth angle $\varphi$. For each of the four $D_{s t} *$ groups of data, we further sort the data into 16 local time subgroups using overlapped 3-h windows of the MLT. Data points in each subgroup cover the 3-h local time sector centered MLT=00:00, 01:30, 03:00,..., and 22:30, respectively. The final step is to bin the magnetic field to obtain the averaged magnetic field vectors on the equally spaced grids in the $\rho-\mathrm{Z}$ plane (the local meridian plane) for each subgroup identified by $D_{s t} *$ and MLT.

Each binning grid in the $\rho-Z$ plane is $0.2 R_{E} \times 0.2 R_{E}$ in size. Depending on the speed of the spacecraft, there are normally a number of one-minute data points within each grid for each spacecraft pass. These data points are taken at nearly the same time and under nearly the same magnetospheric conditions, and thus, are not independent of each other. We use the average of these data points as one independent data point in the final binning. This way we ensure that each spacecraft orbit has equal weight when averaging the magnetic field and all the data points that contribute to the average magnetic field are taken at least $16 \mathrm{~h}$ apart.

To improve the statistics, especially for stronger ring current conditions, we have made the assumption that the ring current distribution is symmetric about the magnetic equator. Under this assumption, the $\mathrm{Z}$ component of the magnetic field $\delta \mathrm{B}_{\mathrm{Z}}$ is symmetric, whereas the other two components $\left(\delta \mathrm{B}_{\rho}, \delta \mathrm{B}_{\varphi}\right)$ are anti-symmetric about the magnetic 
(a) $-20 \mathrm{nT}>$ Dst $^{*}>-40 \mathrm{nT}$

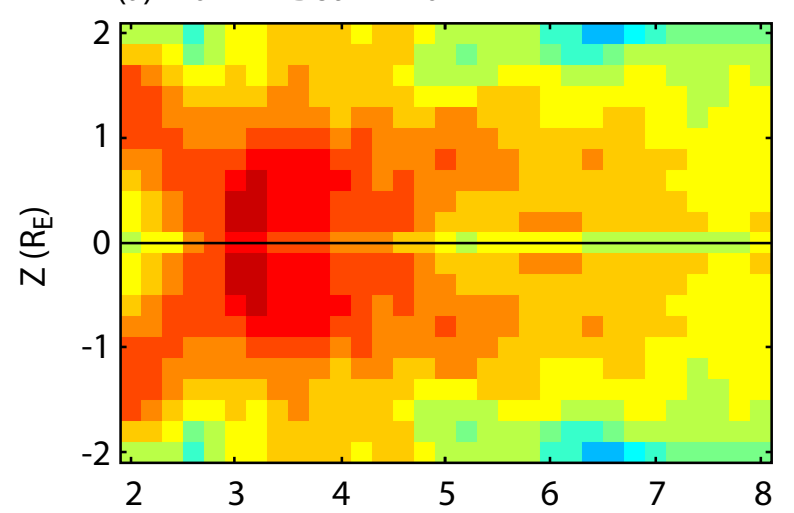

(c) $-60 \mathrm{nT}>\mathrm{Dst}^{*}>-80 \mathrm{nT}$

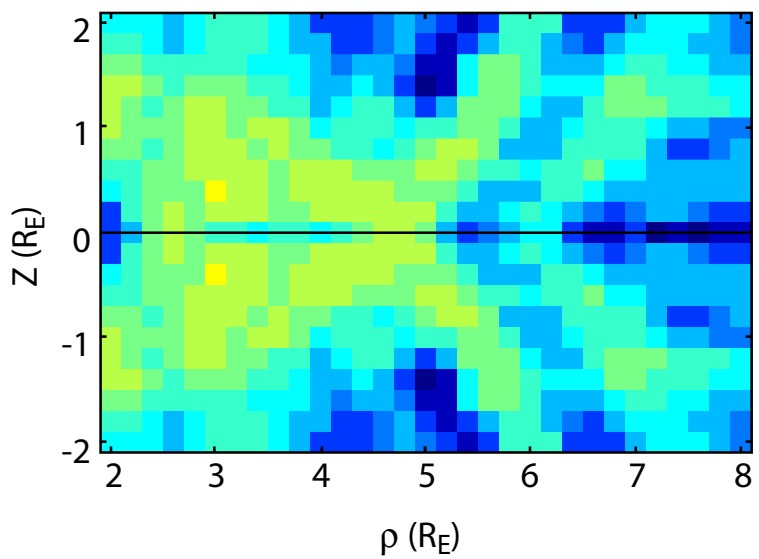

(b) $-40 \mathrm{nT}>$ Dst $^{*}>-60 \mathrm{nT}$

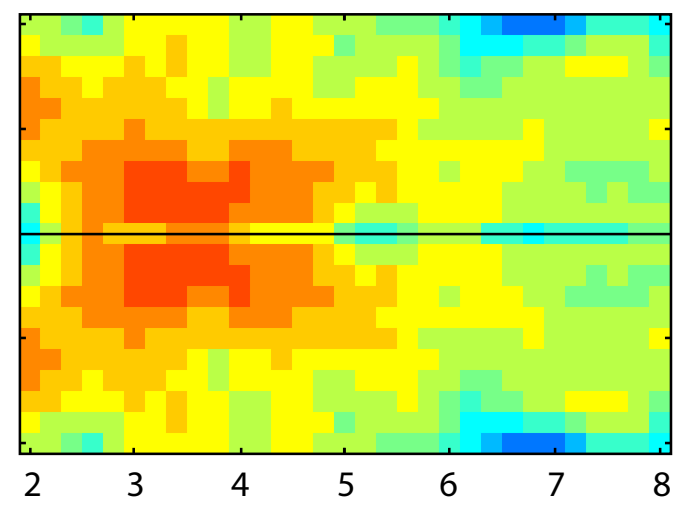

(d) $-80 n T>$ Dst $^{*}>-100 n T$

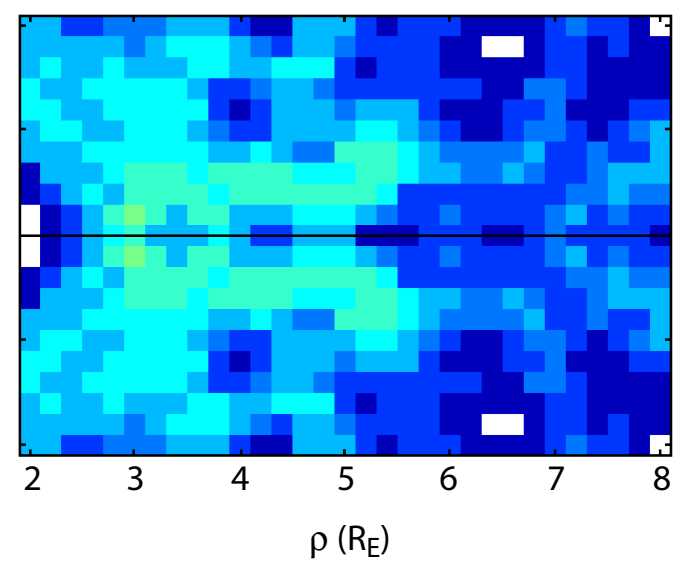

Number of Independent Data Points

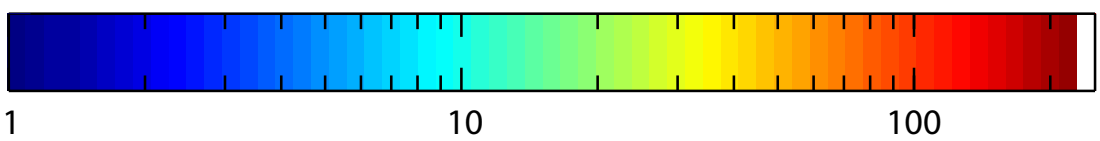

Fig. 3. Data coverage in the midnight plane for the four ranges of $D_{s t} *$ used in this study.

equator. Thus, every independent data point counts twice in the statistics, once at the spacecraft position and the other at its mirror point about the magnetic equator. Specifically, every independent magnetic field data point is placed at two positions, $\left(\delta \mathrm{B}_{\rho}, \delta \mathrm{B}_{\varphi}, \delta \mathrm{B}_{\mathrm{Z}}\right)$ at grid point $(\rho, \varphi, \mathrm{Z})$ and $\left(-\delta \mathrm{B}_{\rho}\right.$, $\left.-\delta \mathrm{B}_{\varphi}, \delta \mathrm{B}_{\mathrm{Z}}\right)$ at grid point $(\rho, \varphi,-\mathrm{Z})$.

Figure 2 presents an example of the data coverage in the midnight (MLT 00:00) local meridian plane for $-40 \mathrm{nT}>D_{s t} *>-60 \mathrm{nT}$. The upper left panel shows the total number of independent data points from all three spacecraft. The three other panels show the individual contributions from Polar, AMPTE/CCE and ISEE, respectively. Each spacecraft complements the others in the spatial coverage. The data from ISEE and AMPTE/CCE are used only for $\rho>2 R_{E}$, because some uncertainty in the spacecraft attitude data affects the quality of the magnetic residual data near the
Earth. The data coverage for the other local time meridian planes are similar for the same $D_{s t} *$ range due to the annual "precession" of the spacecraft orbit around the magnetosphere.

Figure 3 shows the data coverage in the MLT $=00: 00$ local time meridian plane for all four sub-ranges of $D_{s t} *$ between $-20 \mathrm{nT}$ and $-100 \mathrm{nT}$. As expected, nearly half of the data points are in the $D_{s t} *$ range between $-20 \mathrm{nT}$ and $-40 \mathrm{nT}$, a condition typical for quiet time ring current (top left panel). The $D_{s t}$ * range between $-40 \mathrm{nT}$ and $-60 \mathrm{nT}$ represents conditions for moderate magnetospheric disturbances (top right panel). The $D_{s t} *$ ranges between $-60 \mathrm{nT}$ and $-100 \mathrm{nT}$ cover times with moderate magnetic storms and during the recovery phase of larger storms (bottom panels). Most of the moderate storms are the recurrent storms occurring every 27 days (the Sun's rotation period). We note that there are isolated 
holes in the data coverage for $D_{s t} *$ between $-80 \mathrm{nT}$ and $-100 \mathrm{nT}$ (bottom right panel). They are filled with the average of the data points in the neighboring grids, in a procedure to smooth the magnetic field residual vectors. Data points are also present for $D_{s t} *$ greater than $-20 \mathrm{nT}$ and less than $-100 \mathrm{nT}$, but the holes in the data coverage are bigger and cannot be filled completely. They are not included in this study due to the poor statistics.

\section{Magnetic field observations}

The data binning described above provides average perturbation magnetic field vectors at equally spaced grids in meridian planes of 16 magnetic local times. These magnetic residual vectors are caused by various magnetospheric current systems, including the ring current, the magnetopause current, field-aligned currents, and the tail current. Figures $4 \mathrm{a}-$ $\mathrm{d}$ illustrate the magnitude and direction of $\left(\delta \mathrm{B}_{\rho}, \delta \mathrm{B}_{\mathrm{Z}}\right)$, the perturbation magnetic field vectors projected on the meridian plane for the four $D_{s t} *$ ranges, respectively. Note that the magnetic field arrows are plotted using a different scale factor for each different $D_{s t} *$ level. The eight panels for the same $D_{s t} *$ range are grouped in four pairs, each for one meridian plane with the Earth located in between. Also plotted are dipole magnetic field lines with magnetic latitudes at their footprints from $46^{\circ}$ to $70^{\circ}$, at $2^{\circ}$ increments.

From the meridional magnetic field vectors in Figs. $4 \mathrm{a}-\mathrm{d}$, we can visualize the magnetic field lines caused by the external magnetospheric current systems. For all four $D_{s t}$ * ranges, the residual magnetic field in the inner magnetosphere exhibits a local time asymmetry. This is in part caused by the existence of a partial ring current occurring in the nightside sector, and in part by the effect of the tail current. The residual magnetic field strength is much weaker in the dayside than in the nightside. In the dayside sector, the residual magnetic field vectors change gradually from southward to northward as the distance from the Earth increases, thus causing a depression in the Earth's equatorial magnetic field only inside the ring current. In the nightside, the Earth's equatorial magnetic field is depressed throughout the ring current region at all distances due to the tail current. The tail current also changes the direction of the residual magnetic field by stretching the nightside field lines. Thus, the configuration of the magnetic field in the inner magnetosphere is strongly influenced by the tail current, even though this current is quite distant. We note that these fields due to distant currents are curl free and thus, do not contribute to the derived currents in this region.

We now examine $\delta \mathrm{B}_{\varphi}$, the azimuthal component of the magnetic residual vectors. In a dipole field configuration, the magnetic field lines are confined in the meridian plane and the azimuthal component is zero everywhere. In a realistic magnetosphere, the interaction with the solar wind compresses the dayside and creates a long magnetotail in the nightside. The magnetic field lines are twisted azimuthally, except at the noon-midnight meridian plane. The azimuthal twist maximizes in the dawn-dusk meridian plane and is in such a way that the azimuthal field perturbation is eastward in the dawn side and westward in the duskside in the Northern Hemisphere. These perturbations are caused by distant current systems and thus, are curl-free in the inner magnetosphere. In addition, currents flowing in the meridian plane locally, mainly the field-aligned currents, also introduce azimuthal field perturbations near where the currents flow.

Figures 5a-d shows contour images of $\delta \mathrm{B}_{\varphi}$ for the four $D_{s t} *$ ranges, respectively. Only the northern meridian plane is shown. The southern part is anti-symmetric to the northern part, i.e. $\delta \mathrm{B}_{\varphi}$ at any point south of the magnetic equator is equal in magnitude and opposite in sign to that at its northern mirror point. We use the same color scale for the four $D_{s t} *$ levels, and the colors are saturated for large field perturbations $\left|\delta \mathrm{B}_{\varphi}\right|>20 \mathrm{nT}$ in Fig. $5 \mathrm{~d}$. The 8 meridian planes are ordered to emphasize morning-afternoon contrast. For all four levels of geomagnetic disturbances, the maximum $\delta \mathrm{B}_{\varphi}$ magnitude occurs near the dawn-dusk meridian plane, and increases as the level of geomagnetic disturbances becomes higher. In Fig. 5a for low level disturbances, the azimuthal field perturbations are eastward in the dawn side and westward in the dusk side in the region off the equator, mainly corresponding to realistic magnetosphere configuration. At next level of disturbances (Fig. 5b), the effect of the fieldaligned currents appears near the dawn and the dusk. The corresponding $\delta \mathrm{B}_{\varphi}$ is westward in the dawn and eastward in the dusk, mainly at a higher latitude region, thus locally reducing the tailward twisting of the field lines in the region with $\rho>3 R_{E}$. As the level of disturbances increases (Figs. 5c and d), the azimuthal field perturbation associated with the field-aligned currents increases accordingly and eventually becomes dominant near the dawn and the dusk. At the highest disturbance level, the magnetic field lines are twisted sunward locally due to the strong field-aligned currents. The maximum perturbation of the azimuthal magnetic field $\delta \mathrm{B}_{\varphi}$ reaches $-38 \mathrm{nT}$ near dawn (MLT=07:30) and $50 \mathrm{nT}$ near dusk (MLT=19:30).

We now check if the statistical magnetic field patterns presented above are divergence free, since the sorting and averaging used to construct these statistical patterns do not necessarily preserve the divergence free condition of the magnetic field. We calculate the divergence of the average magnetic field residual vectors $(\nabla \cdot \delta \mathbf{B})$ at each grid point and list the values of the mean, median and standard derivations of the results in Table 2. The same unit of $\mathrm{nA} / \mathrm{m}^{2}$ is used for these values, in order to compare them with the derived current density $(\nabla \times \delta \mathbf{B})$ that will be presented in the next two sections. The results in Table 2 show that the divergence of the statistical magnetic field is reasonably small in comparison to the deduced current density. They are in the same order of the statistical noises shown in the derived ring current density patterns, much smaller than the maximum ring current density. 

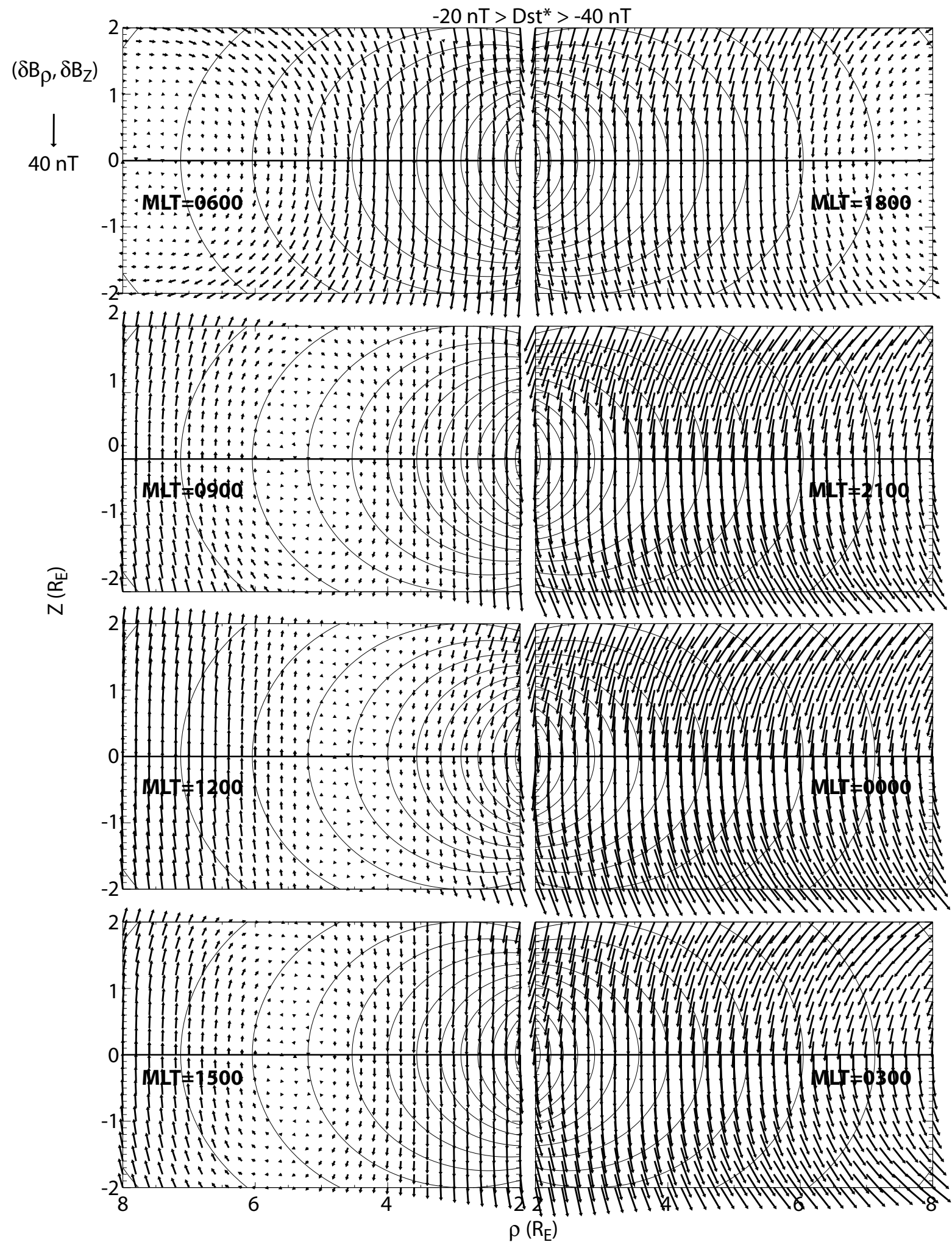

Fig. 4a. Meridional projection of the perturbation magnetic field arrows at equally spaced grids with superimposed dipole field lines in the meridian plane in each of the 8 magnetic local time bins and for each of the four $D_{s t} *$ range: (a) $-20 \mathrm{nT}>D_{s t} *>-40 \mathrm{nT}$. 

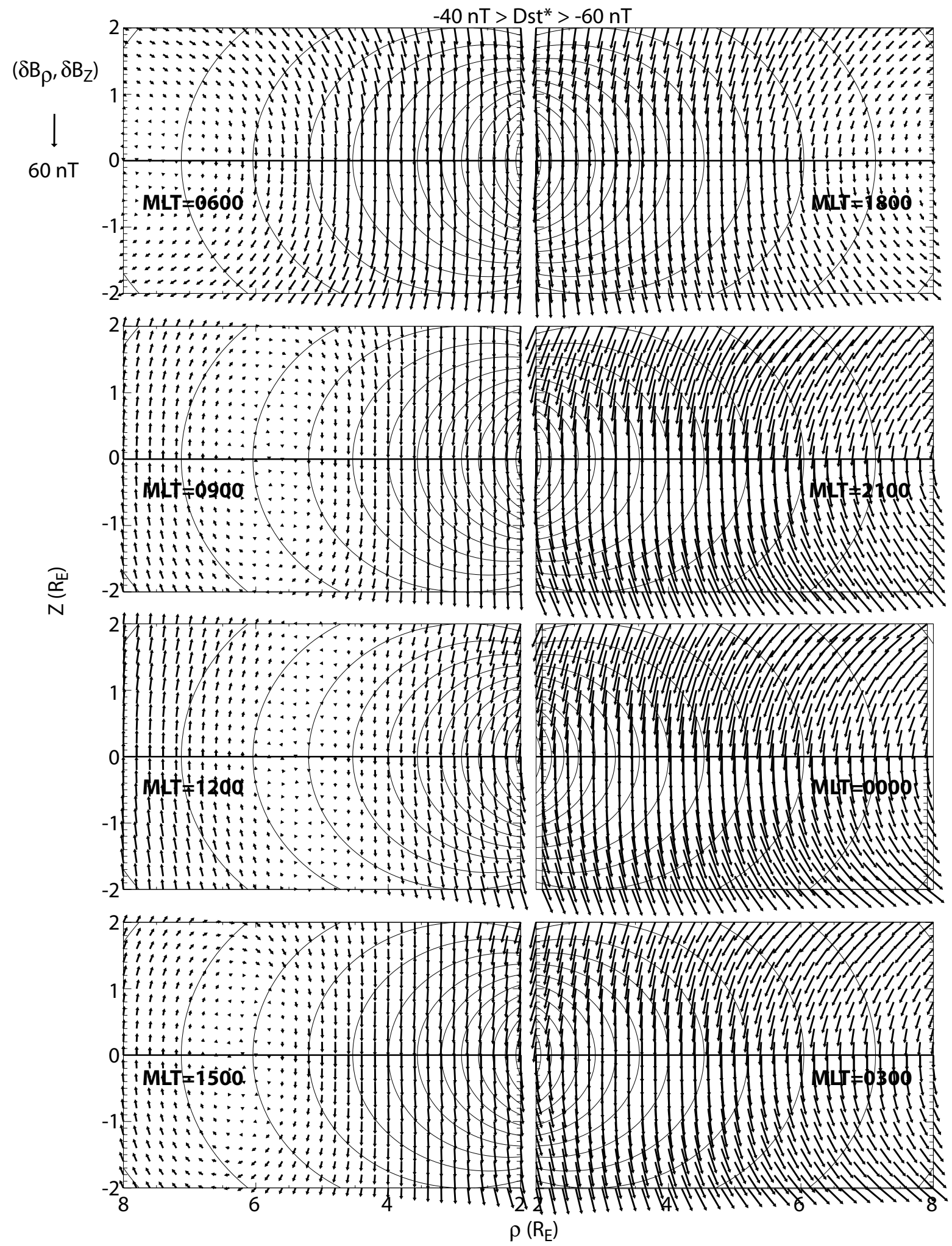

Fig. 4b. Meridional projection of the perturbation magnetic field arrows at equally spaced grids with superimposed dipole field lines in the meridian plane in each of the 8 magnetic local time bins and for each of the four $D_{s t} *$ range: (b) $-40 \mathrm{nT}>D_{s t} *>-60 \mathrm{nT}$. 


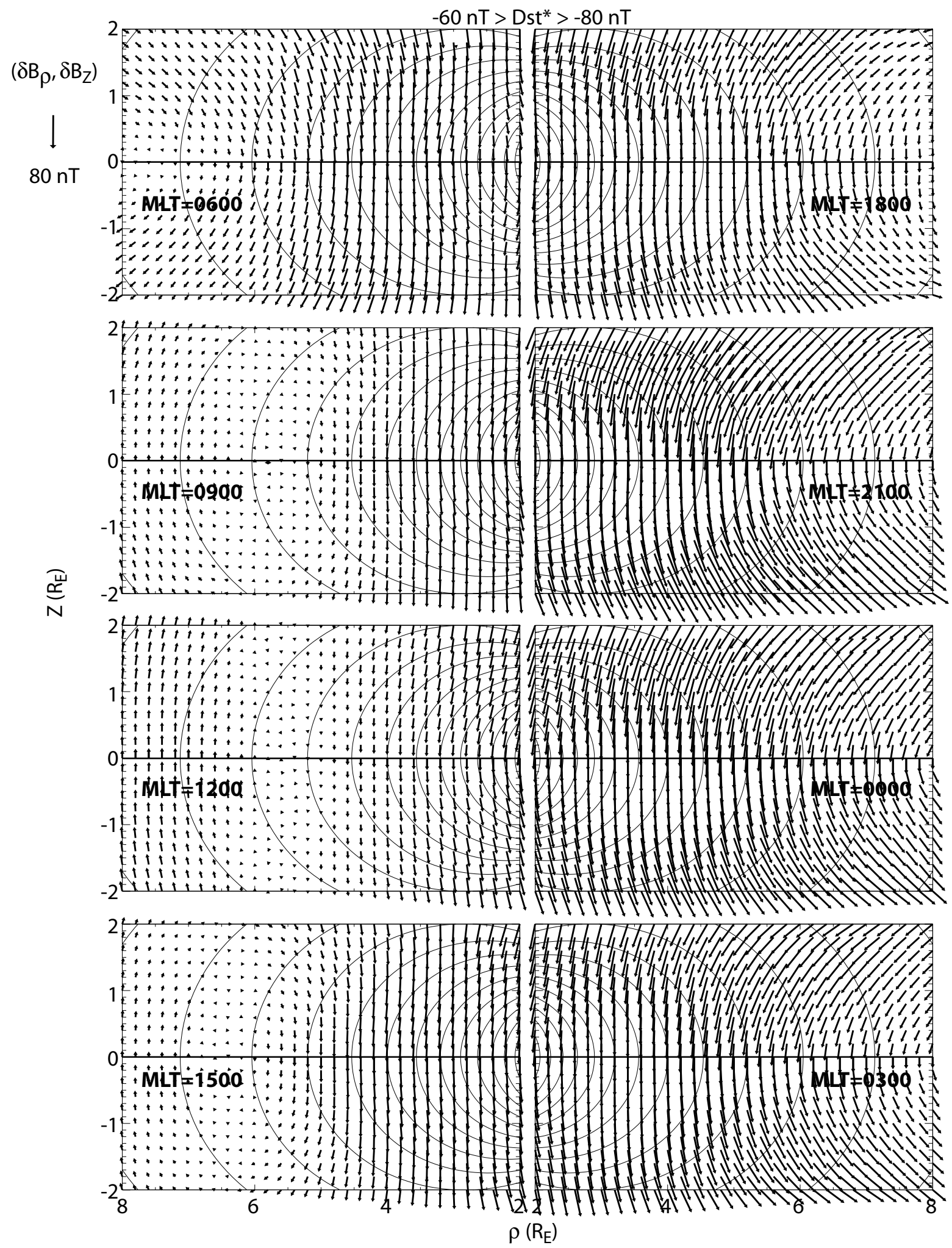

Fig. 4c. Meridional projection of the perturbation magnetic field arrows at equally spaced grids with superimposed dipole field lines in the meridian plane in each of the 8 magnetic local time bins and for each of the four $D_{s t} *$ range: (c) $-60 n T>D_{s t} *>-80 \mathrm{nT}$. 

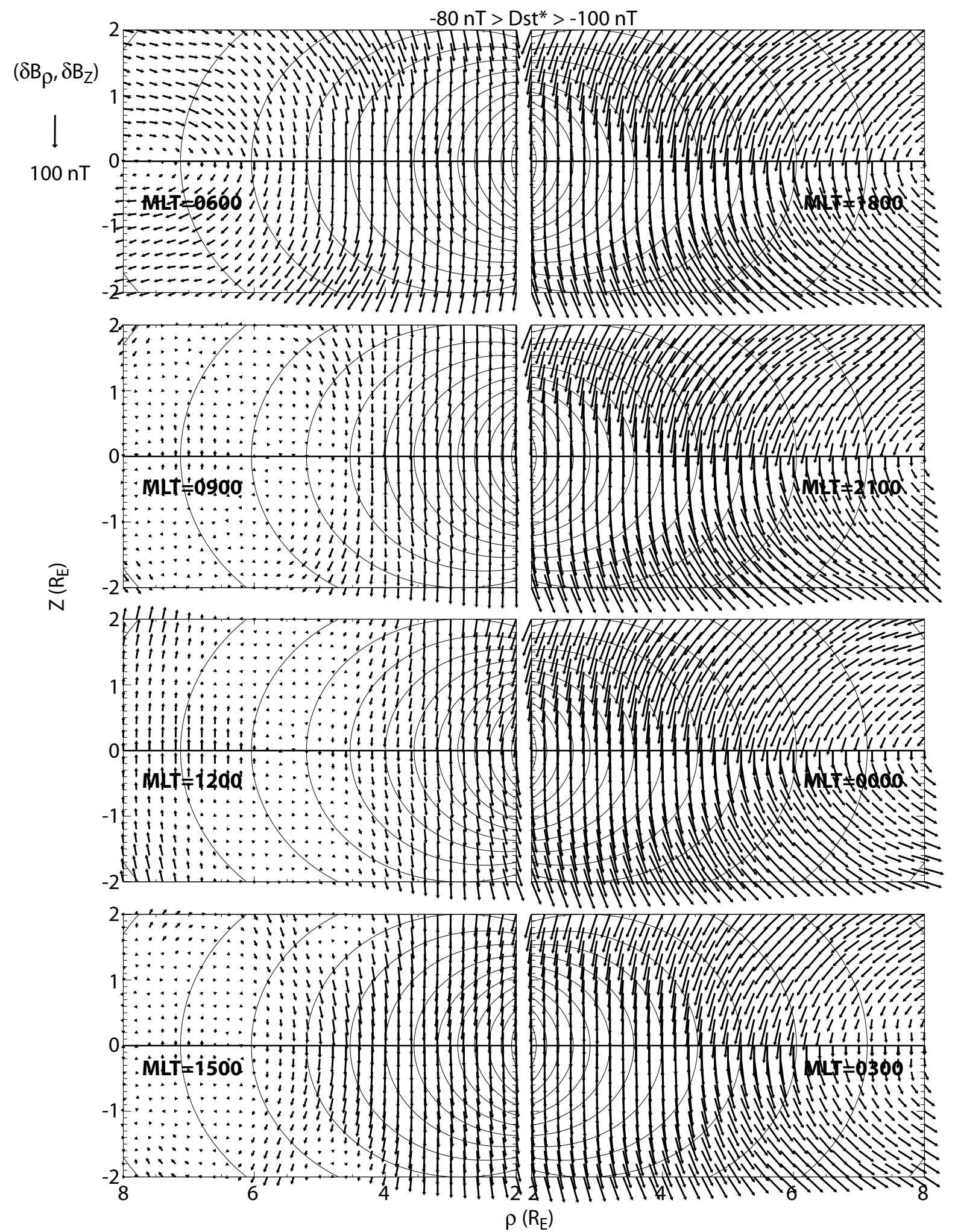

Fig. 4d. Meridional projection of the perturbation magnetic field arrows at equally spaced grids with superimposed dipole field lines in the meridian plane in each of the 8 magnetic local time bins and for each of the four $D_{s t} *$ range: (d) $-80 \mathrm{nT}>D_{s t} *>-100 \mathrm{nT}$. 
Table 2. Mean, Median and Standard Derivation of $\nabla \cdot \delta \mathbf{B}$.

\begin{tabular}{cccccc}
\hline$D_{s t} *(\mathrm{nT})$ & $\nabla \cdot \delta \mathbf{B}\left(\mathrm{nA} / \mathrm{m}^{2}\right)$ & MLT=00:00 & MLT=06:00 & MLT=12:00 & MLT=18:00 \\
\hline \multirow{3}{*}{$(-20,-40)$} & Mean & -0.03 & -0.12 & -0.17 & -0.25 \\
& Median & -0.05 & -0.05 & -0.13 & -0.18 \\
& Std. Dev. & 0.40 & 0.38 & 0.34 & 0.44 \\
\hline \multirow{3}{*}{$(-40,-60)$} & Mean & 0.07 & -0.22 & -0.17 & -0.38 \\
& Median & -0.02 & -0.22 & -0.05 & -0.31 \\
& Std. Dev. & 0.42 & 0.45 & 0.66 & 0.66 \\
\hline & Mean & 0.05 & -0.58 & -0.25 & 0.00 \\
$(-60,-80)$ & Median & 0.08 & -0.68 & -0.24 & 0.20 \\
& Std. Dev. & 0.88 & 1.07 & 0.79 & 1.46 \\
\hline \multirow{3}{*}{ Mean } & -0.05 & -0.091 & -0.50 & -0.18 \\
& Mean & -0.09 & -0.77 & -0.38 & -0.14 \\
& Median & 1.39 & 2.00 & 1.97 & 2.58 \\
\hline
\end{tabular}

$-20 \mathrm{nT}>\mathrm{Dst}^{*}>-40 \mathrm{nT}$
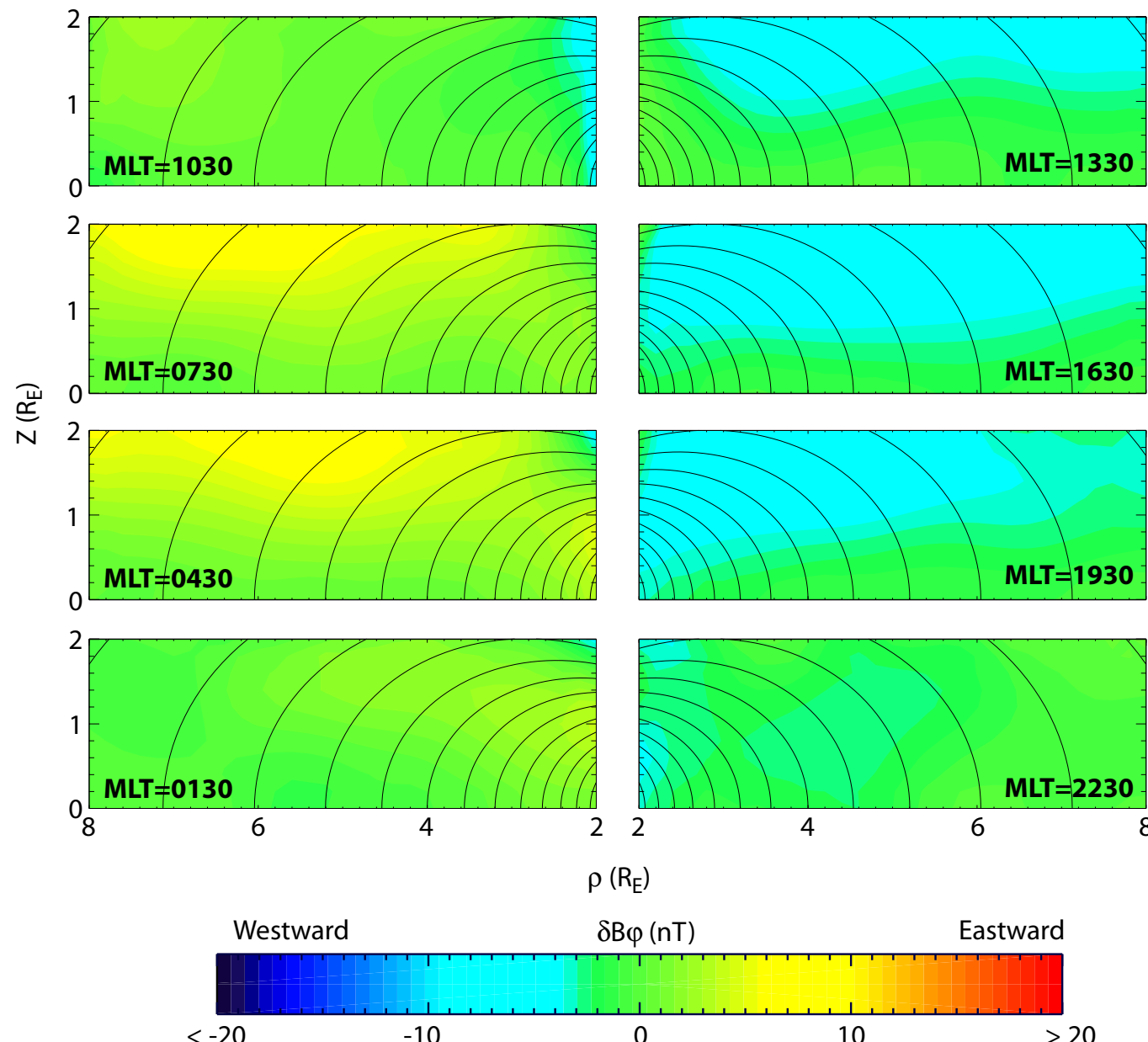

Fig. 5a. Azimuthal component of perturbation magnetic field with superimposed dipole field lines in each of the 8 magnetic local time bins and for each of the four $D_{s t} *$ ranges. Only the northern meridian plane is shown. The southern part is anti-symmetric to the northern part: (a) $-20 \mathrm{nT}>D_{s t} *>-40 \mathrm{nT}$. 
$-40 \mathrm{nT}>\mathrm{Dst}^{*}>-60 \mathrm{nT}$
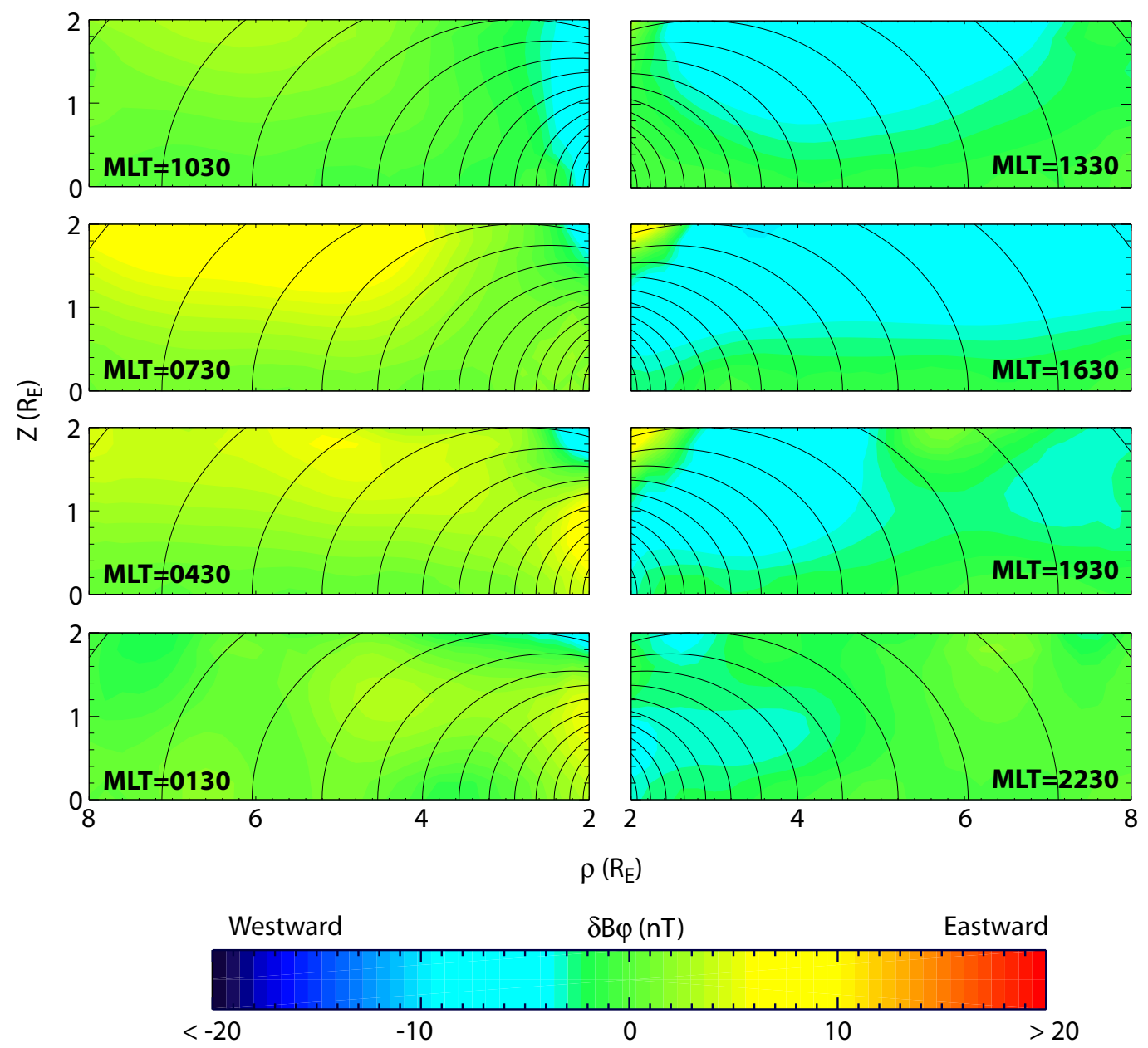

Fig. 5b. Azimuthal component of perturbation magnetic field with superimposed dipole field lines in each of the 8 magnetic local time bins and for each of the four $D_{s t} *$ ranges. Only the northern meridian plane is shown. The southern part is anti-symmetric to the northern part: (b) $-40 \mathrm{nT}>D_{s t} *-60 \mathrm{nT}$.

\section{The symmetric and partial ring currents}

The current density $\mathbf{j}$ can be derived from the curl of the residual magnetic field $\delta \mathbf{B}$, based on Ampere's law. The magnetic field caused by the magnetopause current and the tail current is basically curl-free in the inner magnetosphere. The ring current density can be obtained from the azimuthal component of the curl of $\delta \mathbf{B}$

$\mathrm{j}_{\varphi}=\frac{1}{\mu_{0}}\left(\frac{\partial\left(\delta \mathrm{B}_{z}\right)}{\partial \rho}-\frac{\partial\left(\delta \mathrm{B}_{\rho}\right)}{\partial \mathrm{z}}\right)$,

where positive (negative) $\mathrm{j}_{\varphi}$ is for current flowing westward (eastward).

Figures $6 \mathrm{a}-\mathrm{d}$ show the derived current density in $\mathrm{nA} / \mathrm{m}^{2}$ as the color images for the four $D_{s t} *$ ranges, respectively. We use the same color bar scales for different $D_{s t} *$ levels and let the color saturate for the current density greater than $6 \mathrm{nA} / \mathrm{m}^{2}$ in Figs. 6c and d, to better illustrate the features for various $D_{s t} *$ ranges. We should note that the current density is obtained by taking the derivatives of the magnetic field and is sensitive to statistical noise in the data. Therefore, fine structures in the current density distribution may not be significant, and one should not attempt to obtain such information from this study. The objective of the analysis is to obtain the structure of large-scale current systems. The collective currents integrated over a larger region are more significant and reliable statistically.

For all four $D_{s t} *$ ranges, the derived current consistently shows the existence of an inner ring current flowing eastward in the region $\rho \sim 2-4 R_{E}$, in addition to the main westward ring current. Such an eastward inner ring current has long been predicted to occur at the earthward edge of the plasma sheet, as a result of the negative plasma pressure gradient in the region inside the pressure maximum. It has been observed in the magnetic field data of the DE-1 spacecraft (Nakabe et al., 1997). The eastward ring current enhances the Earth's surface magnetic field. However, the total current is very small. As it should, the inner ring current also exhibits asymmetry in magnetic local time as the westward ring 


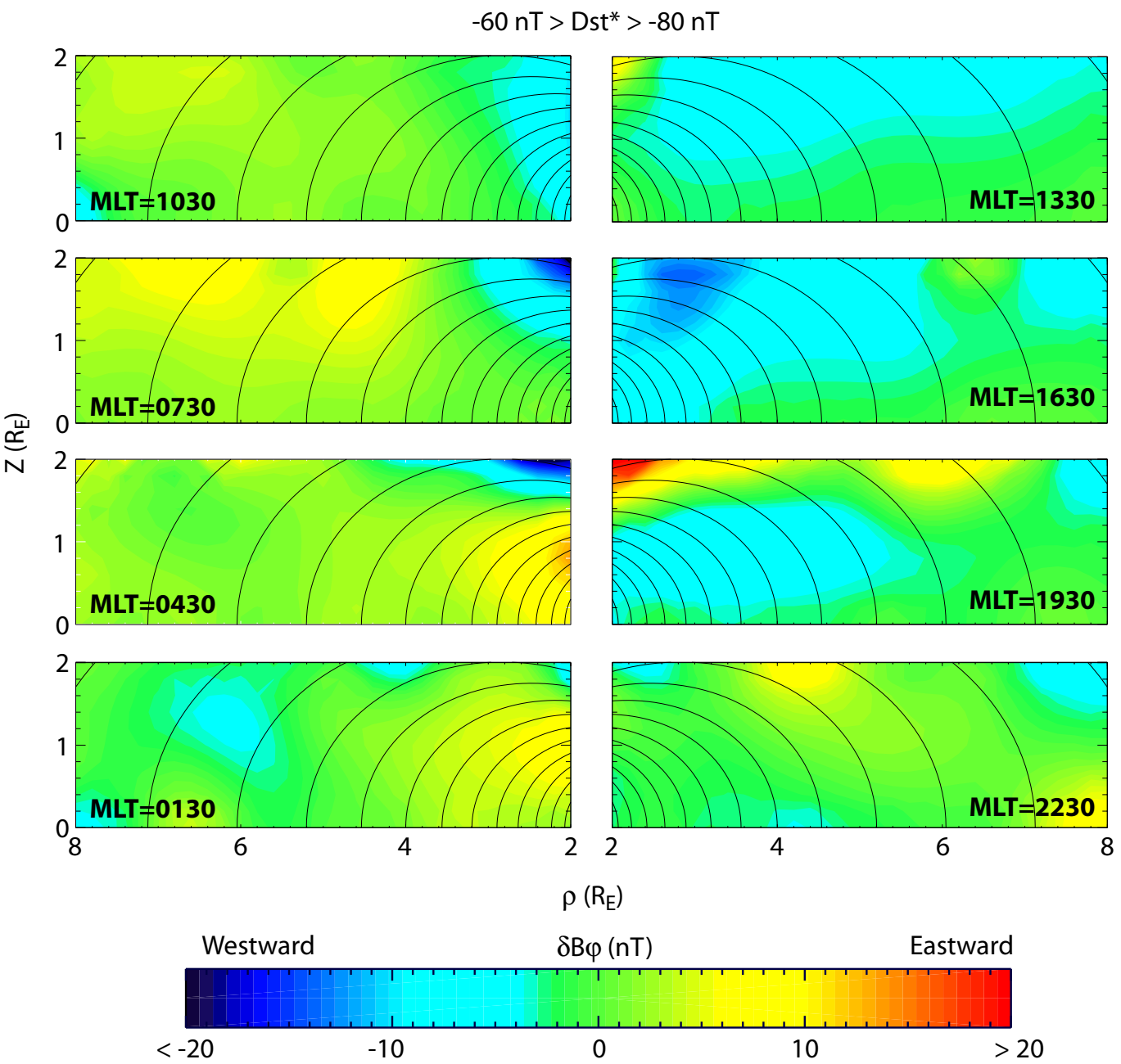

Fig. 5c. Azimuthal component of perturbation magnetic field with superimposed dipole field lines in each of the 8 magnetic local time bins and for each of the four $D_{s t} *$ ranges. Only the northern meridian plane is shown. The southern part is anti-symmetric to the northern part: (c) $-60 \mathrm{nT}>D_{s t} *>-80 \mathrm{nT}$.

current with stronger current in the nightside, and the inner ring current intensifies as the $D_{s t} *$ index decreases. Its peak current density is typically 5 times smaller than that of the main westward ring current. The total current is still smaller, since it is confined in a small cross section compared to the westward ring current, which is distributed over the region $\rho \sim 4-8 R_{E}$. Its major characteristic is a strong asymmetry in magnetic local time due to a partial ring current, regardless of the magnetospheric activity levels. For the quiet time ring current in Fig. 6a, the peak of the westward ring current occurs near the local midnight. The peak appears to move more and more towards the pre-midnight sector as the $D_{s t}$ * index decreases. The peak value reaches $7.6 \mathrm{nA} / \mathrm{m}^{2}$ in Fig. $6 \mathrm{c}$ and $11.0 \mathrm{nA} / \mathrm{m}^{2}$ in Fig. $6 \mathrm{~d}$.

To better illustrate the local time asymmetry of the ring current distribution, Fig. 7 shows the equatorial current intensity for the four $D_{s t} *$ ranges. The current intensity here is the total current per meter along $\rho$ in a finite-thickness equatorial disc. Its value is obtained by integrating the cur- rent density in the Z-direction from $-1.6 R_{E}$ to $1.6 R_{E}$, the main region for the westward ring current. This calculation slightly underestimates the total current intensity for the inner ring current, which is mainly confined within $1 R_{E}$ from the magnetic equator, and the current above $1 R_{E}$ flowing in the opposite direction decreases the number. The calculation also underestimates the total current intensity for the main westward current because the current density in the region above $1.6 R_{E}$ is not negligible. Nevertheless, Fig. 7 clearly shows the characteristics of the ring current's local time distribution. Please note that different color scales are used in the four panels to accommodate the large variations in the ring current intensity for different $D_{s t} *$ ranges. Figure 8 repeats this display using a logarithmic color scale that remains fixed across the four panels.

The main ring current appears to become increasingly asymmetric as it develops during the magnetic storms, as evident by the contrast of the nightside maximum to the dayside minimum intensities in the ring. It is mainly the partial ring 


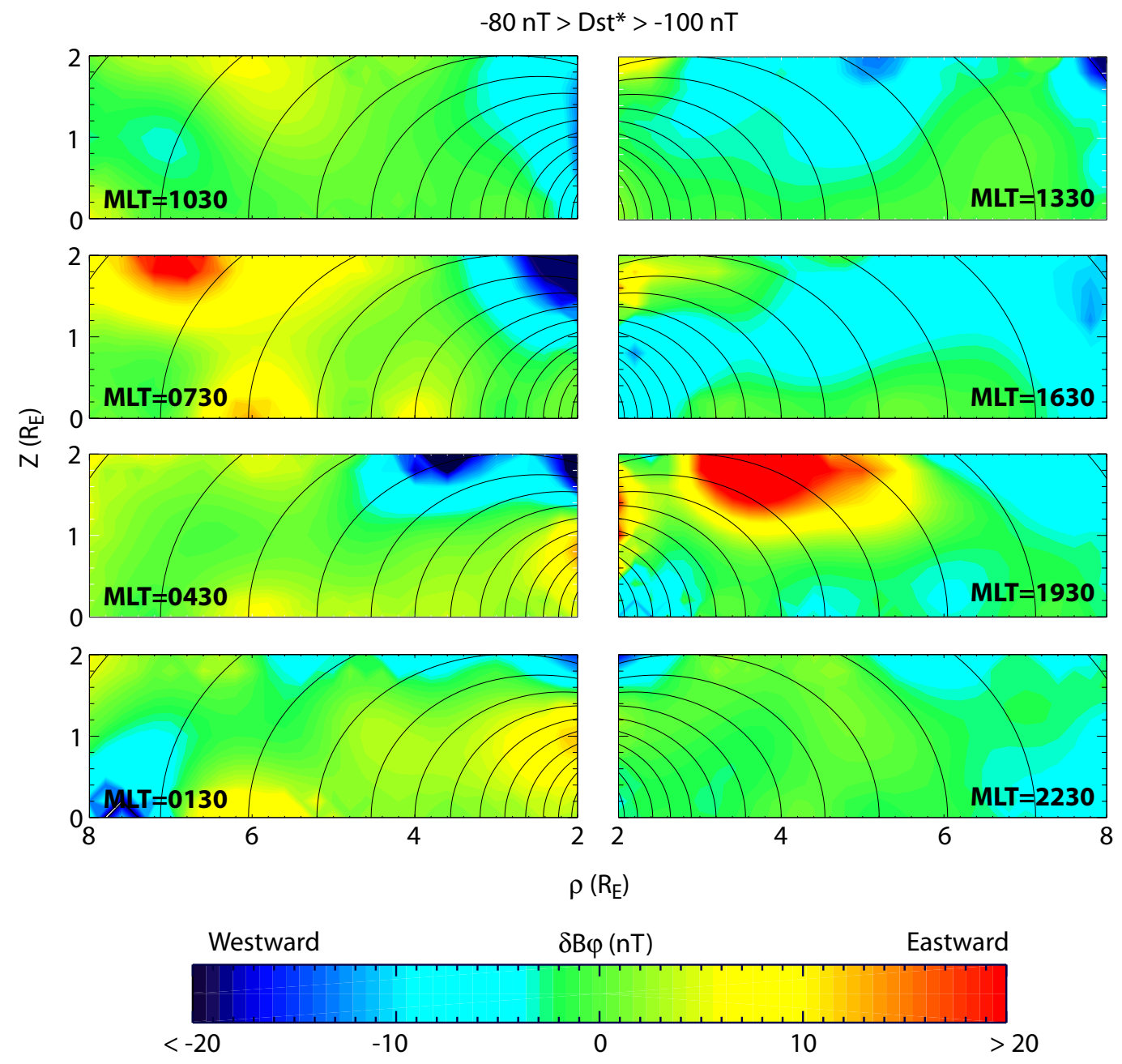

Fig. 5d. Azimuthal component of perturbation magnetic field with superimposed dipole field lines in each of the 8 magnetic local time bins and for each of the four $D_{s t} *$ ranges. Only the northern meridian plane is shown. The southern part is anti-symmetric to the northern part: (d) $-80 \mathrm{nT}>D_{s t}{ }^{*}>-100 \mathrm{nT}$.

current that becomes more intense at a higher disturbance level. Meanwhile, the peak of the current intensity shifts earthwards, in addition to the duskward move observed in Figs. 7 and 8. During the quiet time, the partial ring current is distributed nearly symmetrically around the local midnight and is centered at $\rho \sim 6 R_{E}$ (panel (a)). In contrast, the partial ring current is most significantly intensified in the premidnight sector, and the bulk of the partial ring current moves to $\rho \sim 5 R_{E}$ during moderate magnetic storms (panel (d)).

The effect of the erosion of the dayside magnetosphere during moderate magnetic storms is also evident in the two bottom panels (c) and (d) of Figs. 7 and 8. An eastward current gradually appears in the dayside to within $\rho \sim 8 R_{E}$ as the ring current intensifies, especially for the smallest $D_{s t}$ * range in panel (d) $\left(-80 \mathrm{nT}>D_{s t} *>-100 \mathrm{nT}\right)$. It is apparently a part of the magnetopause current system. During the quiet times or northward IMF conditions, the typical magnetopause subsolar distance is $10.3 R_{E}$ (Petrinec and Russell, 1996). The inward motion of the magnetopause can be caused by an increase in the solar wind dynamic pressure or/and by the dayside reconnection under persistent southward IMF conditions that transfers the dayside magnetic flux to the nightside. For moderate storms, especially recurrent ones, the interplanetary magnetic field is generally southward but the solar wind dynamic pressure is normal. The magnetopause moves earthward as the reconnection occurs in the dayside magnetopause under southward IMF conditions.

The total westward ring current can be estimated by integrating the current density over most of the area of the current flows. Since the westward ring current flows mainly in the region from 4 to $8 R_{E}$ in the cylindrical radial distance, we obtain the total westward ring current by integrating all the westward current density $\left(\mathrm{j}_{\varphi}>0\right)$ over the area from 4 to $8 R_{E}$ in $\rho$ and -2 to $2 R_{E}$ in Z. Figure 9 shows a polar plot of the total westward ring current as a function of the magnetic local time for the four $D_{s t} *$ ranges. In the polar plot, the radial distance of the curve at a particular azimuth angle represents the total current at the corresponding magnetic local time. 


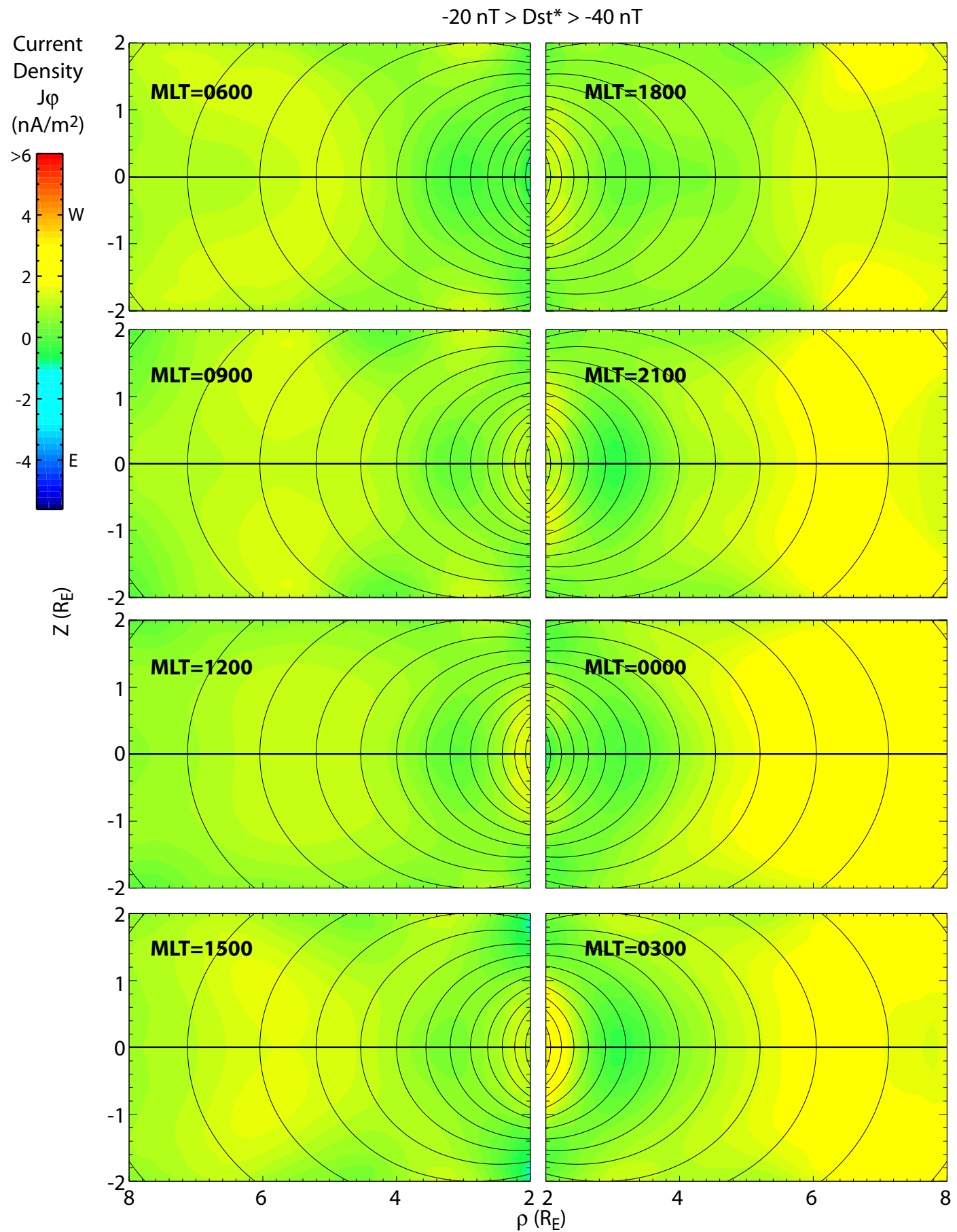

Fig. 6a. Azimuthal component of the current density (or the ring current density) with superimposed dipole field lines for each of the four $D_{s t} *$ levels: (a) $-20 \mathrm{nT}>D_{s t} *>-40 \mathrm{nT}$. 

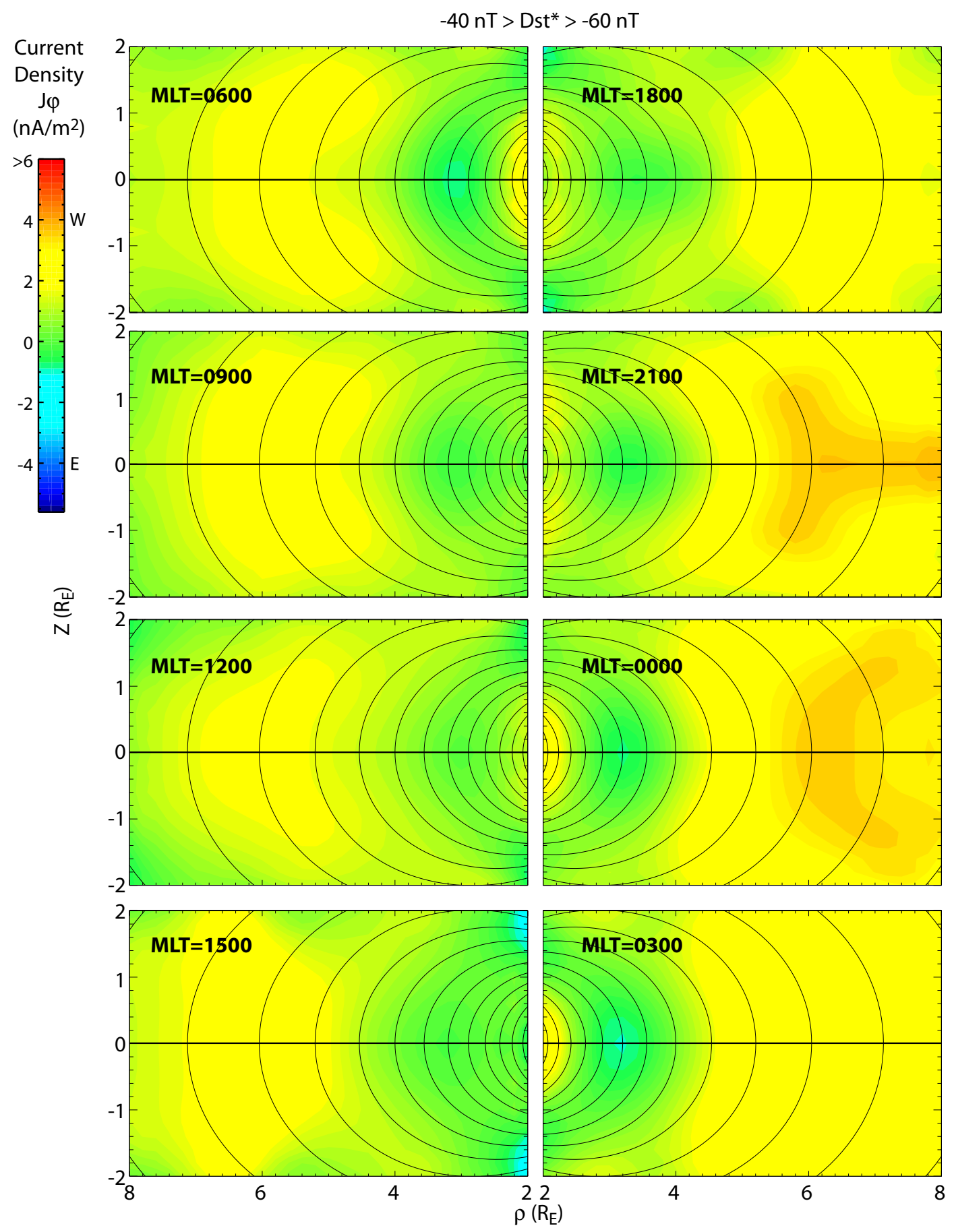

Fig. 6b. Azimuthal component of the current density (or the ring current density) with superimposed dipole field lines for each of the four $D_{s t}{ }^{*}$ levels: (b) $-40 \mathrm{nT}>D_{s t} *-60 \mathrm{nT}$. 


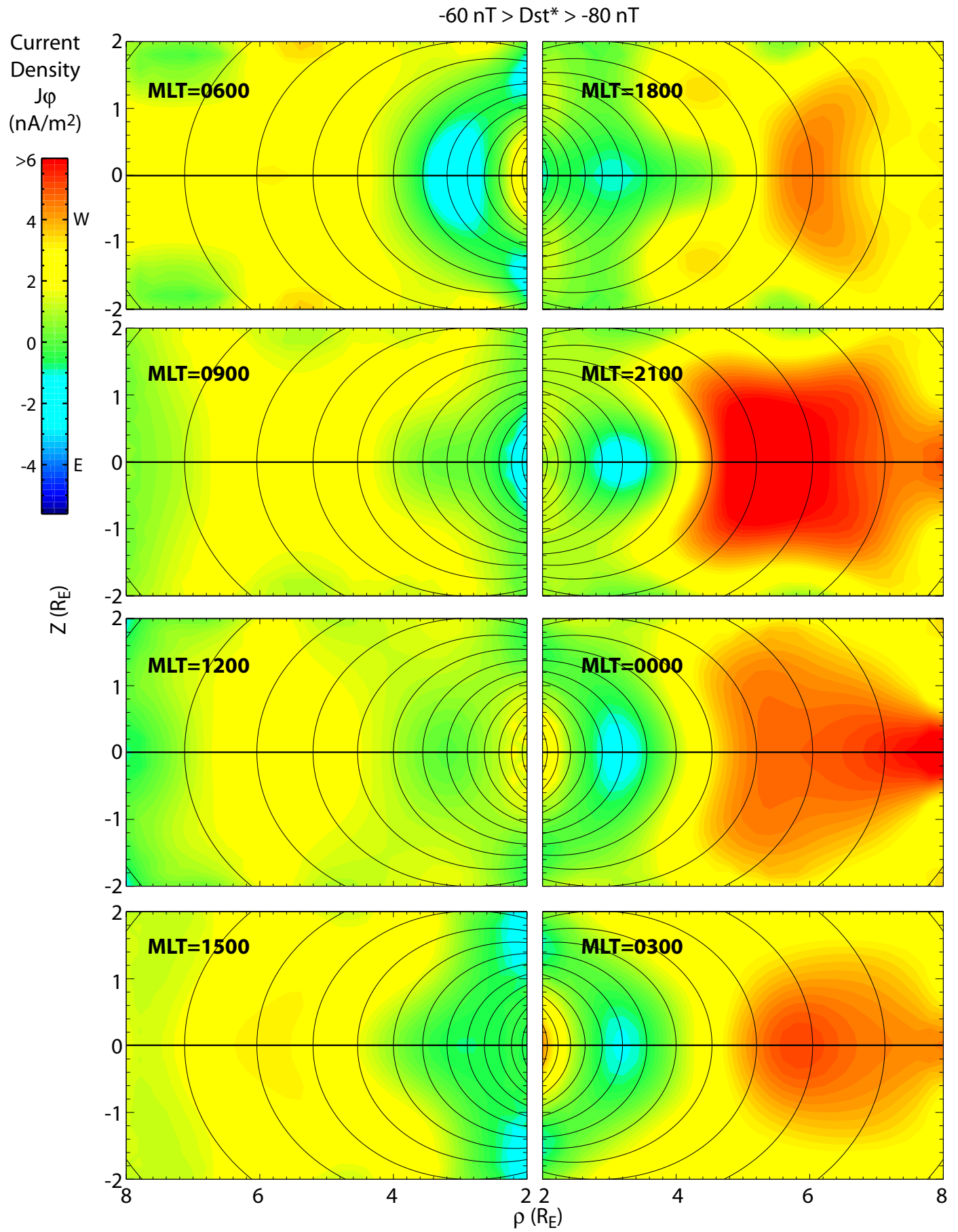

Fig. 6c. Azimuthal component of the current density (or the ring current density) with superimposed dipole field lines for each of the four $D_{s t}{ }^{*}$ levels: (c) $-60 \mathrm{nT}>D_{s t} *>-80 \mathrm{nT}$. 


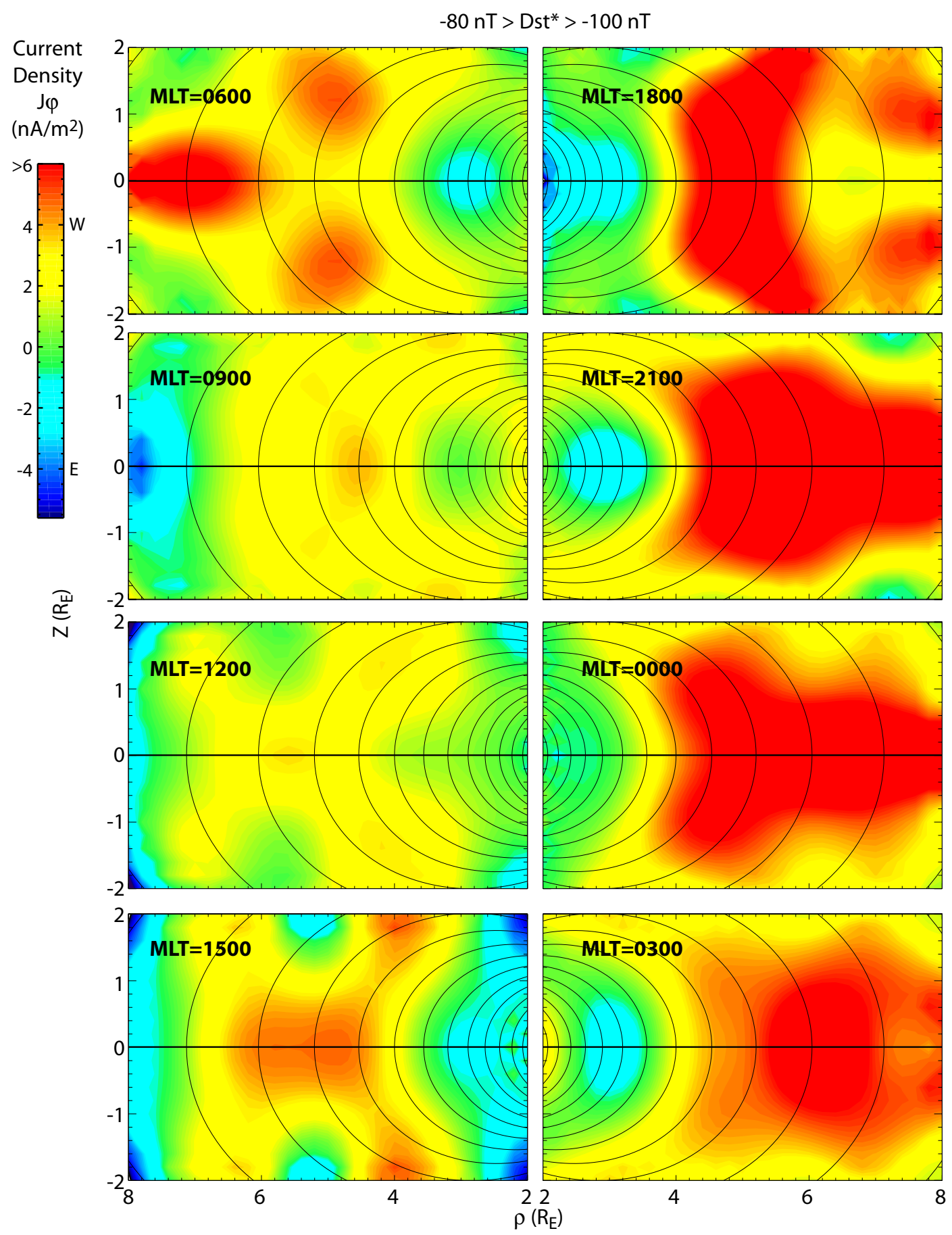

Fig. 6d. Azimuthal component of the current density (or the ring current density) with superimposed dipole field lines for each of the four $D_{s t}{ }^{*}$ levels: d) $-80 \mathrm{nT}>D_{s t}{ }^{*}>-100 \mathrm{nT}$. 
Equatorial Ring Current Intensity

$\left(-1.6 R_{E}<Z<1.6 R_{E}\right)$

(a) $-20 \mathrm{nT}>$ Dst $^{*}>-40 \mathrm{nT}$

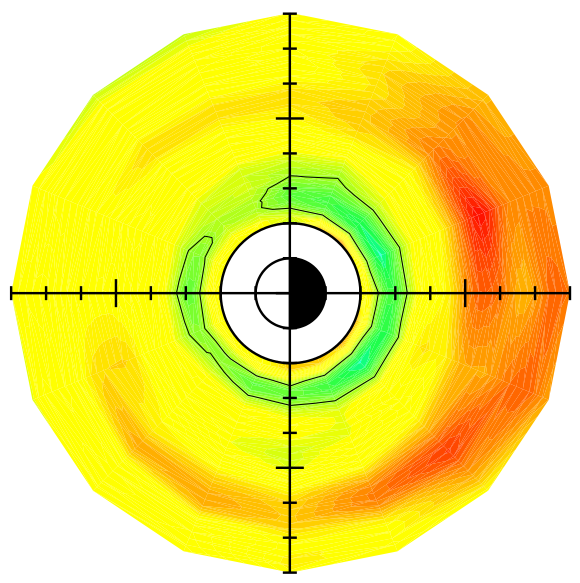

(c) $-60 \mathrm{nT}>$ Dst $^{*}>-80 \mathrm{nT}$

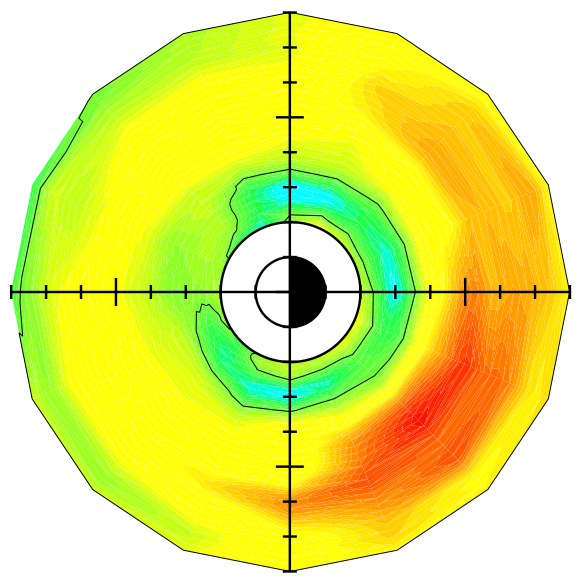

(b) $-40 \mathrm{nT}>$ Dst $^{*}>-60 \mathrm{nT}$
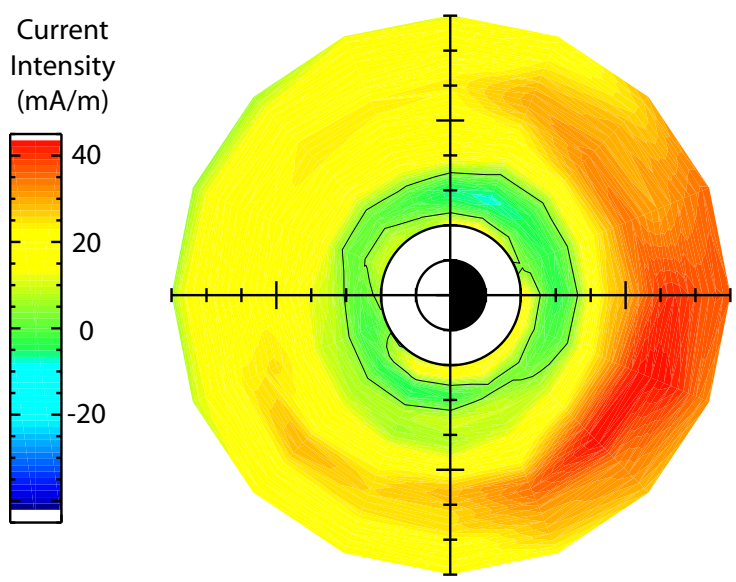

Current Intensity $(\mathrm{mA} / \mathrm{m})$

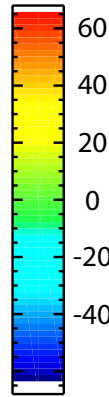

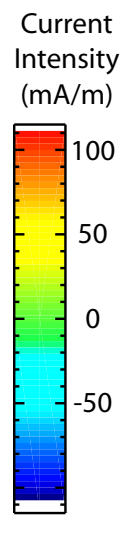

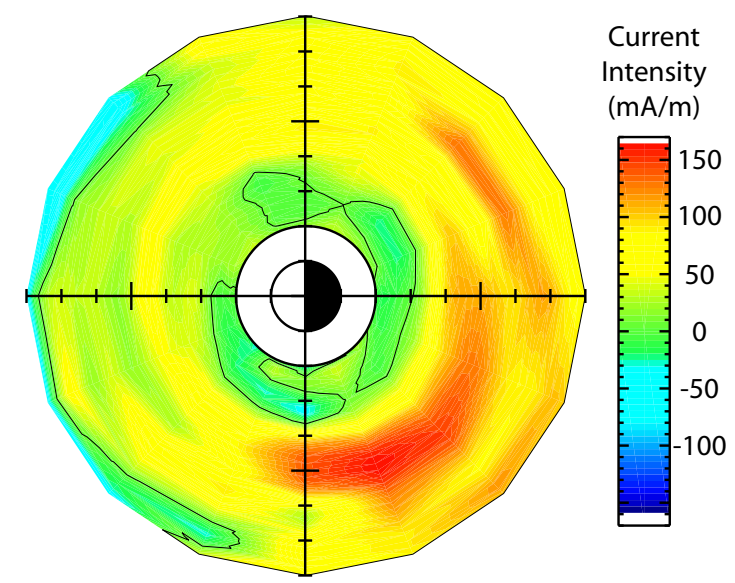

Fig. 7. Equatorial ring current intensity as a function of magnetic local time and distance from the dipole axis for each of the four $D_{S t} *$ levels. The current intensity is calculated by integrating the azimuthal component of the current density over $-1.6<Z<1.6 R_{E}$. The color bar is linear and differs for each panel.

During quiet time $\left(-20 \mathrm{nT}>D_{s t} *>-40 \mathrm{nT}\right)$, the total westward current is $\sim 0.5 \mathrm{MA}$ in the dayside and $\sim 1 \mathrm{MA}$ near the midnight. In such a case, the symmetric ring current and the partial ring current are similar in strength. The partial ring current is centered near the local midnight. As the disturbance level increases for the three smaller $D_{s t} *$ ranges, we note that the strength of the symmetric ring current (i.e. the dayside value) increases to the similar level, $\sim 0.8 \mathrm{MA}$. In contrast, the partial ring current (i.e. the nighttime value with the dayside value subtracted) exhibits a most drastic increase in strength, which is strongly dependent on the $D_{s t} *$ index. Thus, it is mainly the partial ring current that contributes to the varying depression of the Earth's surface magnetic field, and the consequent decrease in the $D_{s t}$ index during mag- netic storms. The partial ring current is present everywhere in the nightside, but its peak shifts from the midnight to the pre-midnight sector as the partial ring current strengthens. For the range $-80 \mathrm{nT}>D_{s t}{ }^{*}>-100 \mathrm{nT}$, the peak of the partial ring current moves to $\sim 19: 30$ MLT. The total current at the peak reaches $\sim 3.4 \mathrm{MA}$, in which $\sim 0.8 \mathrm{MA}$ for the symmetric ring current and $\sim 2.6 \mathrm{MA}$ for the partial ring current.

\section{Closure of the partial ring current}

The existence of the partial ring current requires a fieldaligned current system to close the diverging part of the ring current through the ionosphere. The current circuit indicates 


\section{Equatorial Ring Current Intensity}

$\left(-1.6 R_{E}<Z<1.6 R_{E}\right)$

(a) $-20 n T>$ Dst $^{*}>-40 n T$

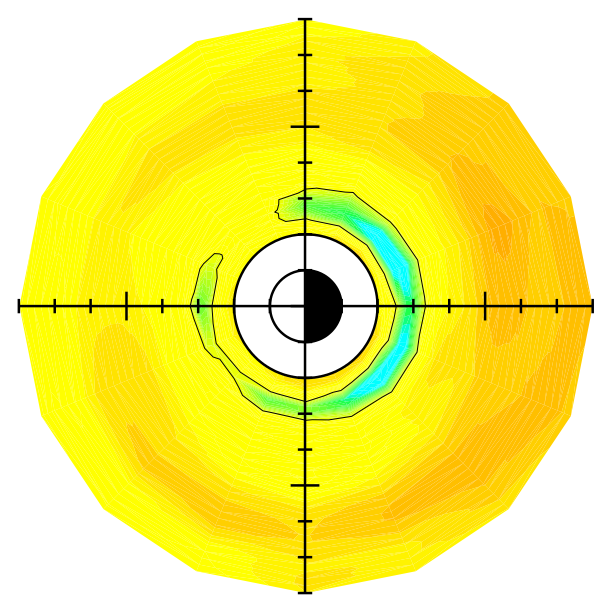

(c) $-60 \mathrm{nT}>\mathrm{Dst}^{*}>-80 \mathrm{nT}$

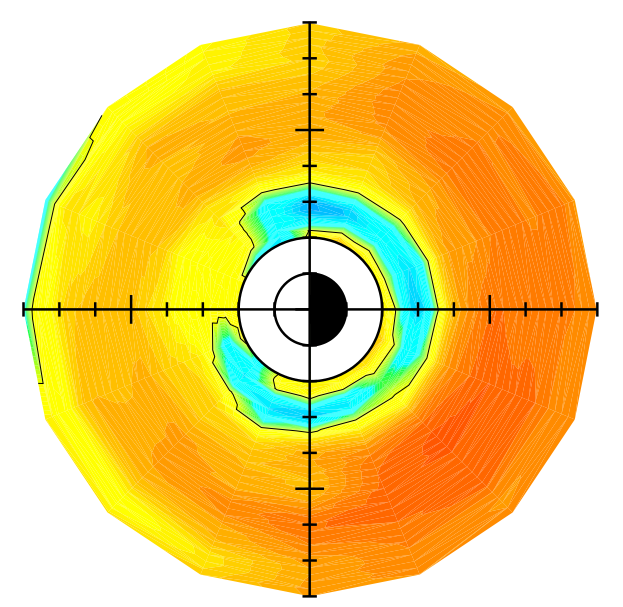

(b) $-40 \mathrm{nT}>$ Dst $^{*}>-60 \mathrm{nT}$

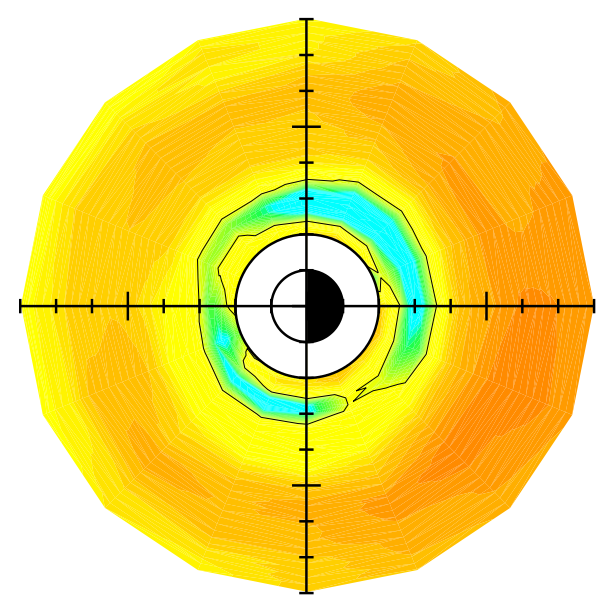

(d) $-80 n T>$ Dst $^{*}>-100 n T$

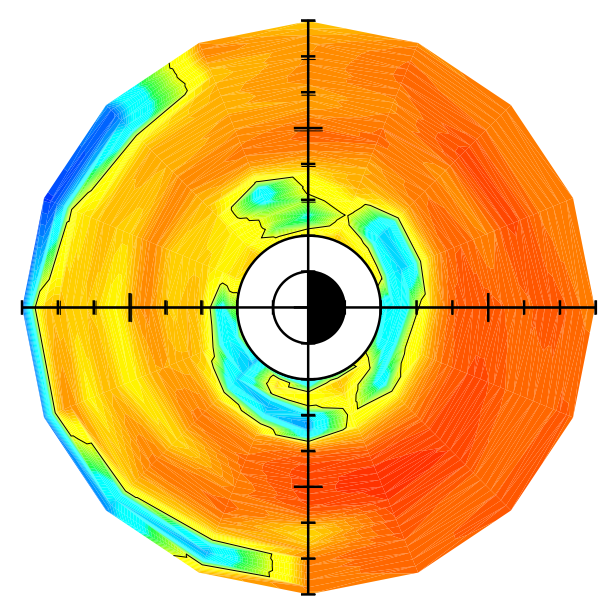

Current

Intensity

$(\mathrm{mA} / \mathrm{m})$

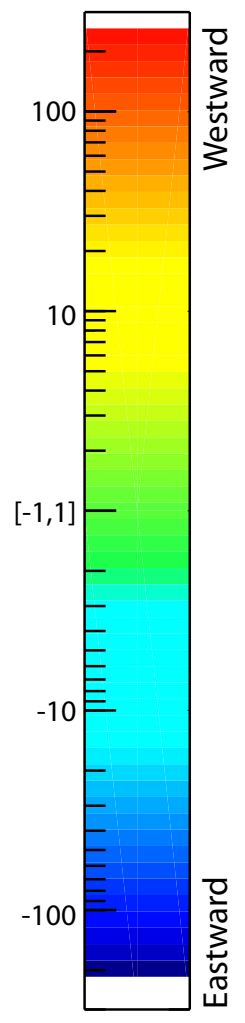

Fig. 8. Equatorial ring current intensity as a function of magnetic local time and distance from the dipole axis for each of the four $D_{s t}{ }^{*}$ levels. A logarithmic scale for the color bar has been chosen and is kept constant for each panel.

that the partial ring current is closed by the field-aligned currents flowing downward into the ionosphere in the premidnight sector and upward out of the ionosphere in the post-midnight sector. The sense of the directions and the location suggest that they are consistent with the region 2 field-aligned currents. The earthward movement of the partial ring current peak also indicates that the closure region 2 field-aligned current maps to lower latitudes at a higher disturbance level.

The closure field-aligned currents occur mainly in the local times where the ring current has maximum divergence, or the largest local time variation. It is evident in Fig. 9 that the field-aligned currents maximize at local times near the dawn and dusk, and minimize near the noon and midnight. This is also consistent with the observation of the azimuthal com- ponent of the magnetic field in Figs. 5a-d. We can use our binned average perturbation magnetic field data to calculate the current density for the current flowing in the meridian plane using the curl of $\delta \mathbf{B}$ as:

$$
\begin{aligned}
& \mathrm{j}_{\rho}=\frac{1}{\mu_{0}}\left(\frac{\partial\left(\delta \mathrm{B}_{\mathrm{z}}\right)}{\rho \partial \varphi}-\frac{\partial\left(\delta \mathrm{B}_{\varphi}\right)}{\partial \mathrm{z}}\right) \\
& \mathrm{j}_{z}=\frac{1}{\mu_{0}}\left(\frac{\partial\left(\rho \delta \mathrm{B}_{\varphi}\right)}{\rho \partial \rho}-\frac{\partial\left(\delta \mathbf{B}_{\rho}\right)}{\rho \partial \varphi}\right),
\end{aligned}
$$

where $\mathrm{j}_{\rho}$ and $\mathrm{j}_{z}$ are the current density components along the $\rho$ and $\mathrm{Z}$ direction. The results of the calculations are presented in Figs. 10a-d for each of the 8 local time planes for the four levels of $D_{s t} *$ used in the study. The arrows represent the magnitude and the direction of $\left(\mathrm{j}_{\rho}, \mathrm{j}_{\mathrm{Z}}\right)$ vectors. Note 


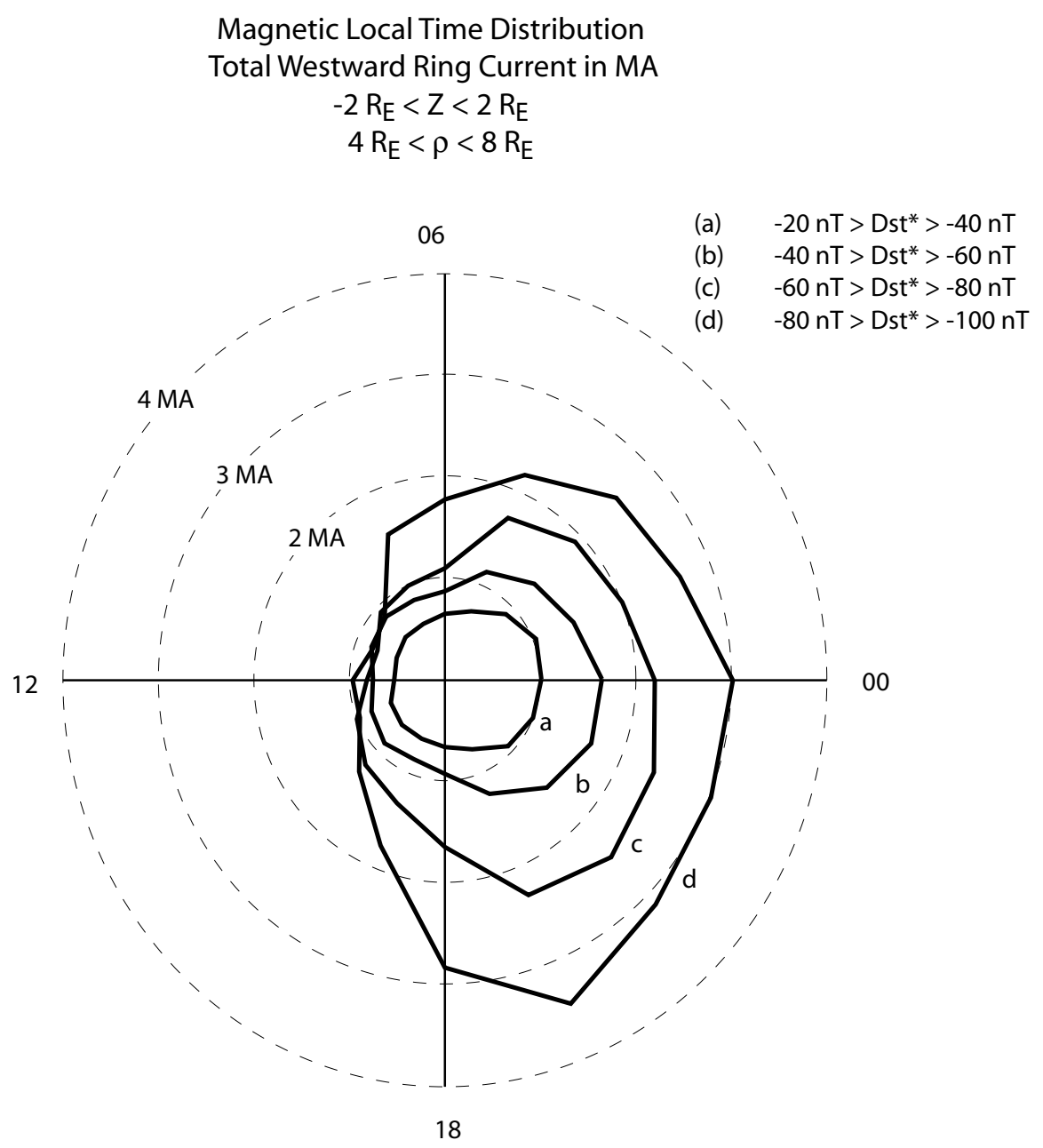

Fig. 9. Polar plot of the total westward flowing ring current obtained by integrating the current density from 4 to $8 R_{E}$ in $\rho$ and from -2 to 2 in $Z$ and plotting versus local time for each of the four ranges in $D_{s t}$.

the calibration factors for the current density are different for different $D_{s t} *$ ranges.

Figure 10a shows that the meridional current density is strongest at low altitudes, as it should be due to the convergence of the magnetic field. It is strongest in the 03:00 and 06:00 LT planes where it is flowing upward out of the atmosphere. The strongest downward currents occur at 18:00 and 21:00 LT. At other local times (daytime and local midnight), the current is much reduced.

Figure $10 \mathrm{~b}$ shows the same display for the next higher level of disturbance, $-40 \mathrm{nT}>D_{s t} *>-60 \mathrm{nT}$. The scale on the current arrow has been increased by a factor of 2 . The current flow is very similar to that in Fig. 10a, but the currents (accounting for the scale change) are somewhat stronger. Figures 10c-d show the two higher levels of geomagnetic activity and they, too, are qualitatively the same as the two lower levels of activity but with even stronger currents. We note that we have checked that the currents found herein are divergence free, as they should be, if they are derived from the curl of a magnetic field.
The displays in Figs. 10a-10d emphasize the similarity of the current patterns across all levels of geomagnetic activity by rescaling the current vector. If we instead keep the current scale fixed and choose the most active plane (the dawndusk plane), we can illustrate how the meridional currents strengthen as the level of disturbance increases, as we show in Fig. 11. Again, we see very little change in the pattern, except that the pattern shifts to lower latitudes, just a rescaling of the level of activity.

\section{Discussion and conclusions}

Our examination of 20 years of magnetospheric magnetic field data has allowed us to quantify how the ring current flows and closes in the magnetosphere at a variety of disturbance levels. The ring current density deduced from magnetic field observations includes total currents carried by plasma from all species over the entire energy spectrum. The study confirms certain expectations and alters others. There are two ring currents, an inner one that flows eastward and 


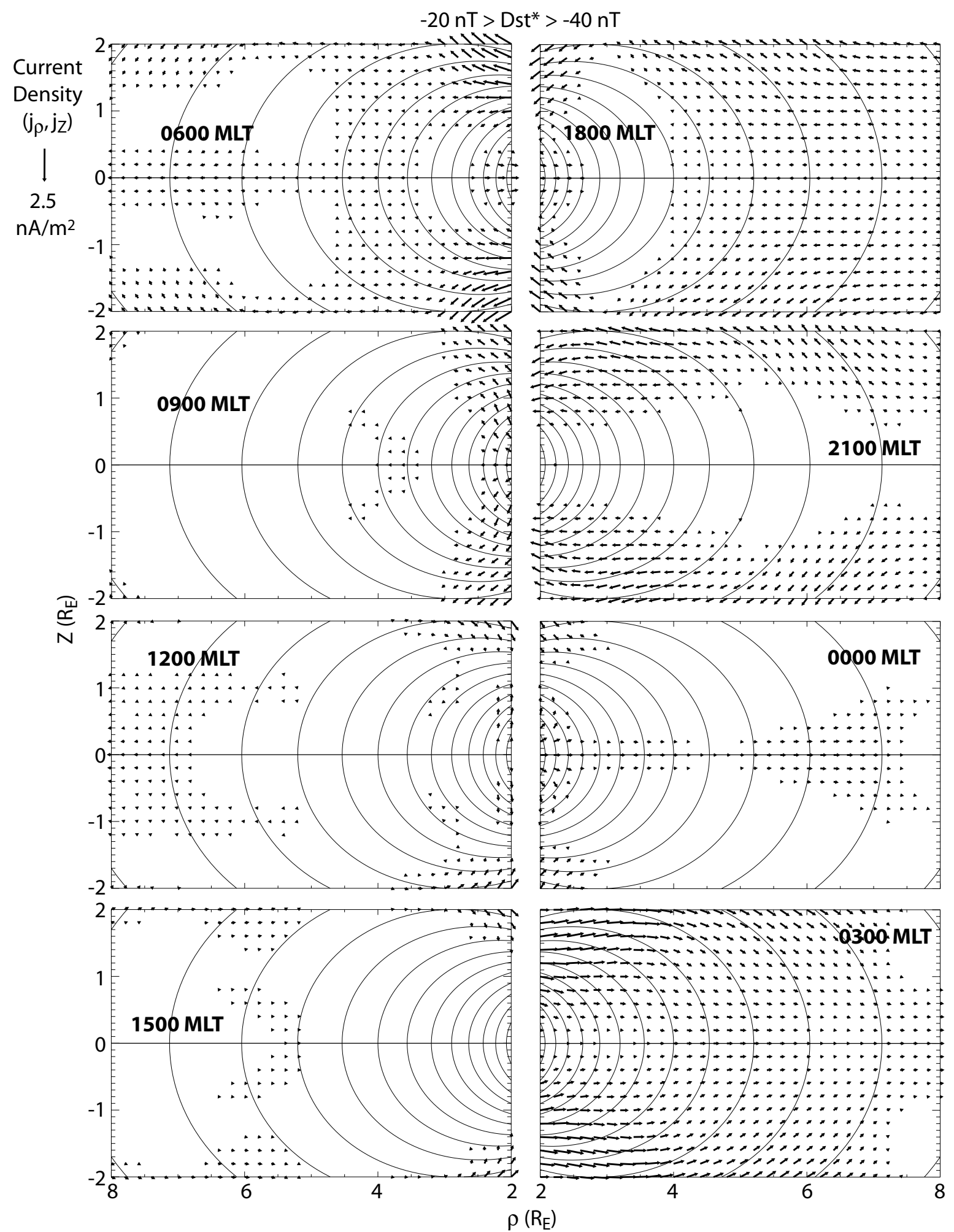

Fig. 10a. Meridional components of the current density as arrows in equally spaced grids in each of the 8 local time planes with superimposed dipole field lines for the four $D_{s t} *$ levels. The scale factor for the current density is different for different $D_{s t} *$ : (a) $-20 \mathrm{nT}>D_{s t} *>-40 \mathrm{nT}$. 


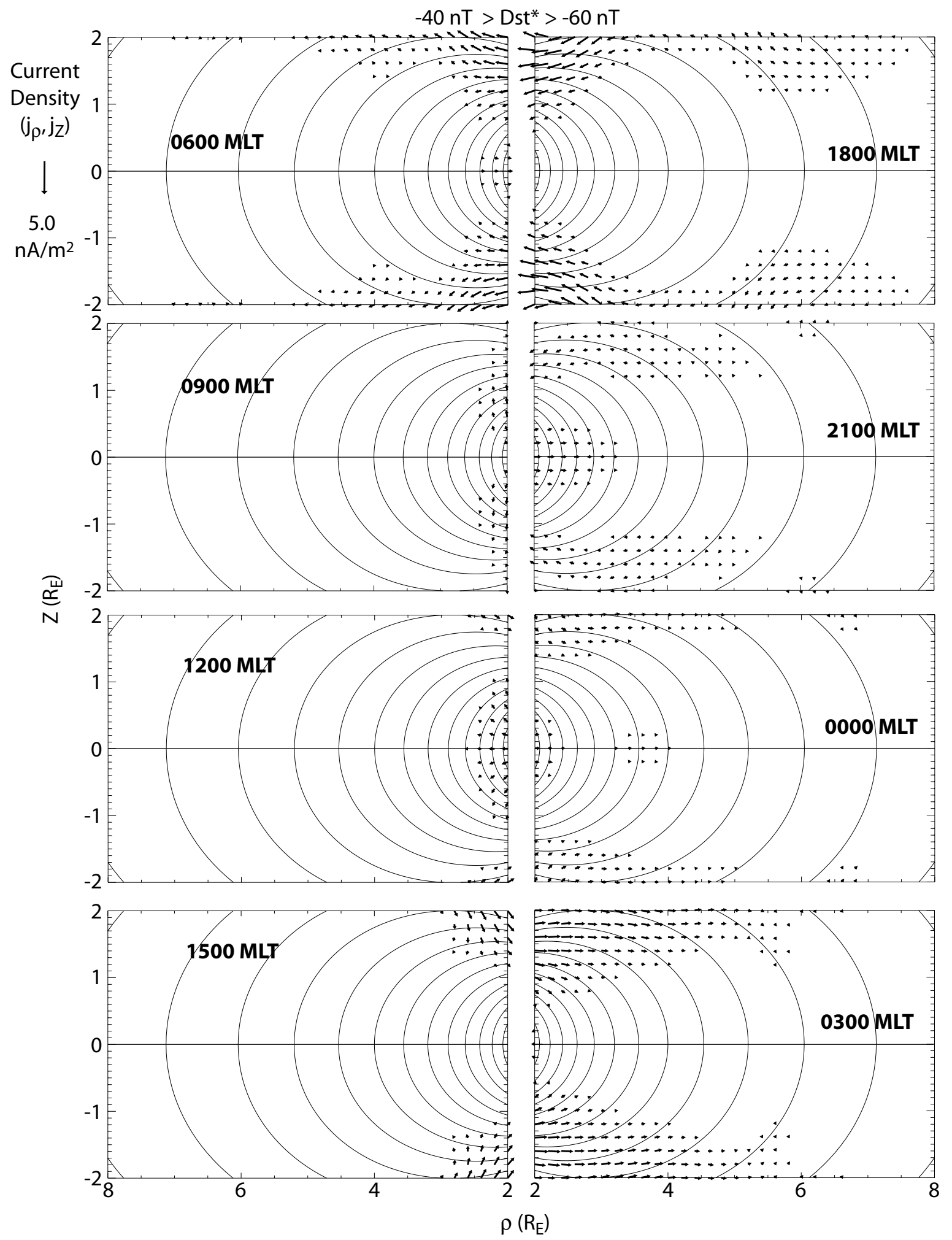

Fig. 10b. Meridional components of the current density as arrows in equally spaced grids in each of the 8 local time planes with superimposed dipole field lines for the four $D_{s t} *$ levels. The scale factor for the current density is different for different $D_{s t} *:(\mathrm{b})-40 \mathrm{nT}>D_{s t} *>-60 \mathrm{nT}$. 


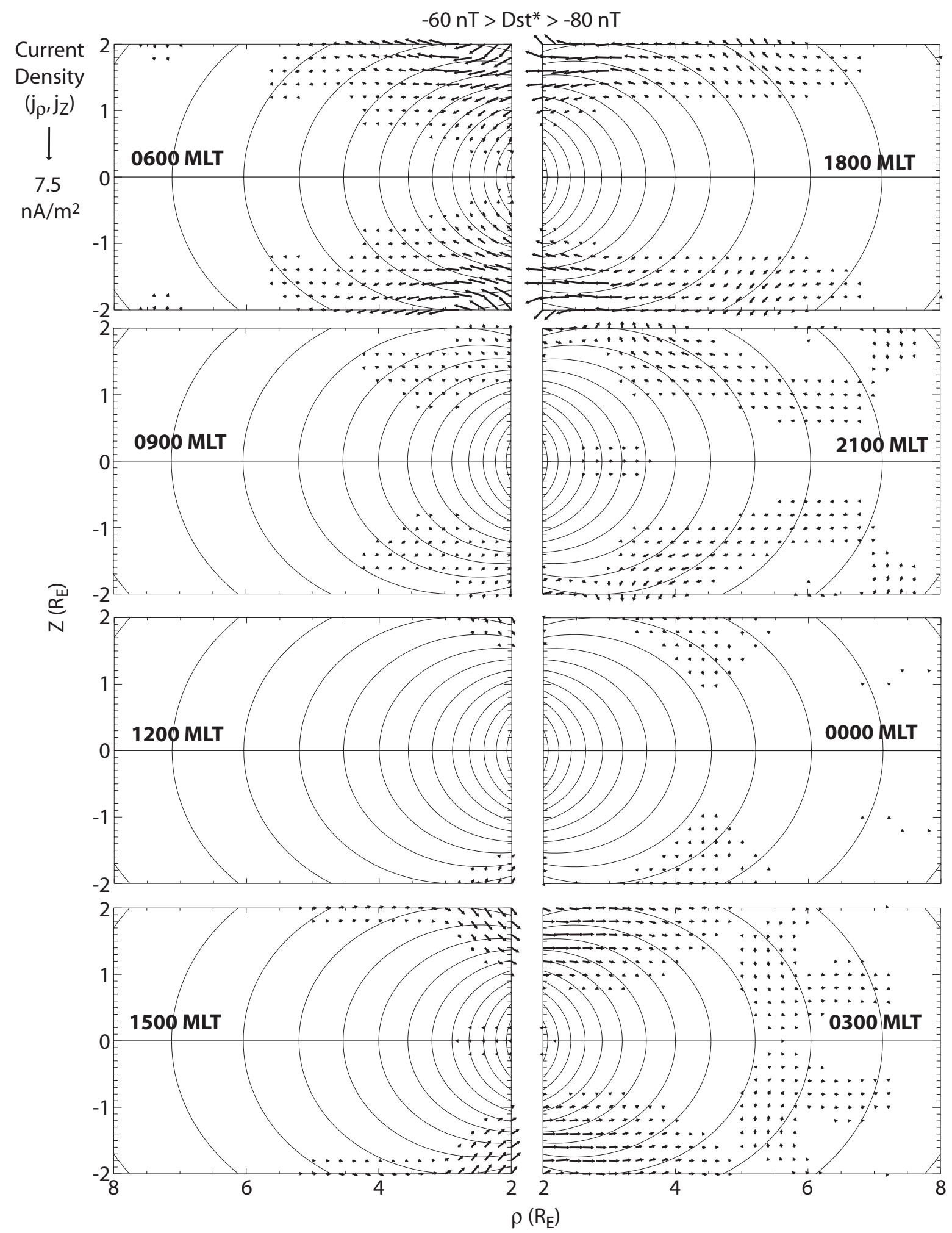

Fig. 10c. Meridional components of the current density as arrows in equally spaced grids in each of the 8 local time planes with superimposed dipole field lines for the four $D_{s t} *$ levels. The scale factor for the current density is different for different $D_{s t} *$ level. (c) $-60 \mathrm{nT}>D_{s t} *>-80 \mathrm{nT}$. 


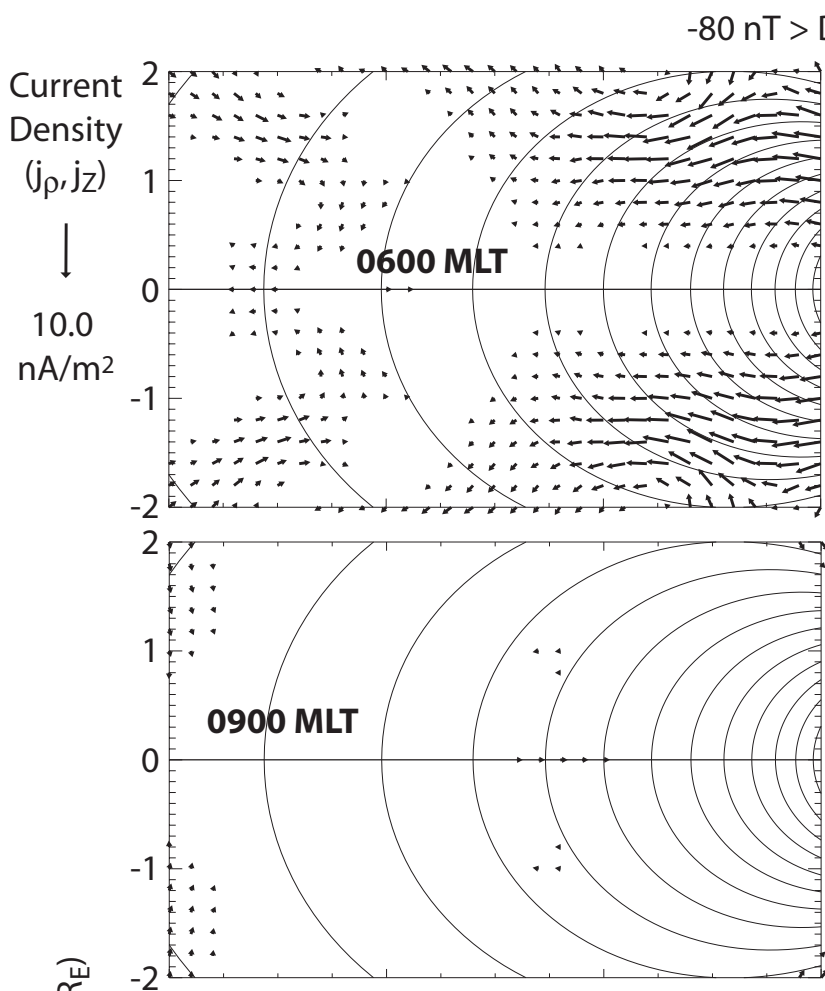

$s t^{*}>-100 n T$

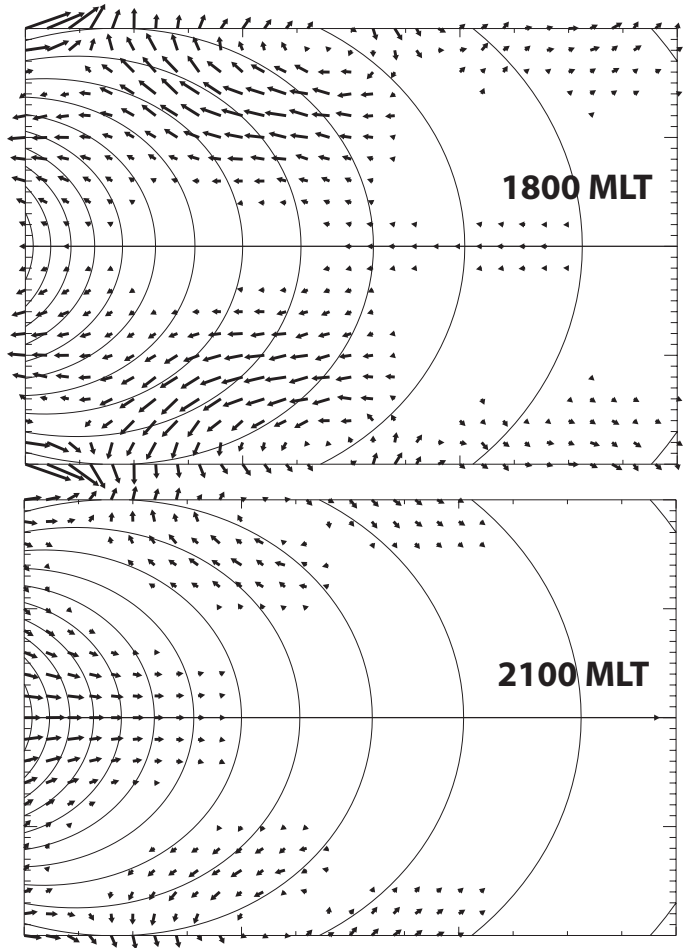

$\stackrel{\sim}{N}$
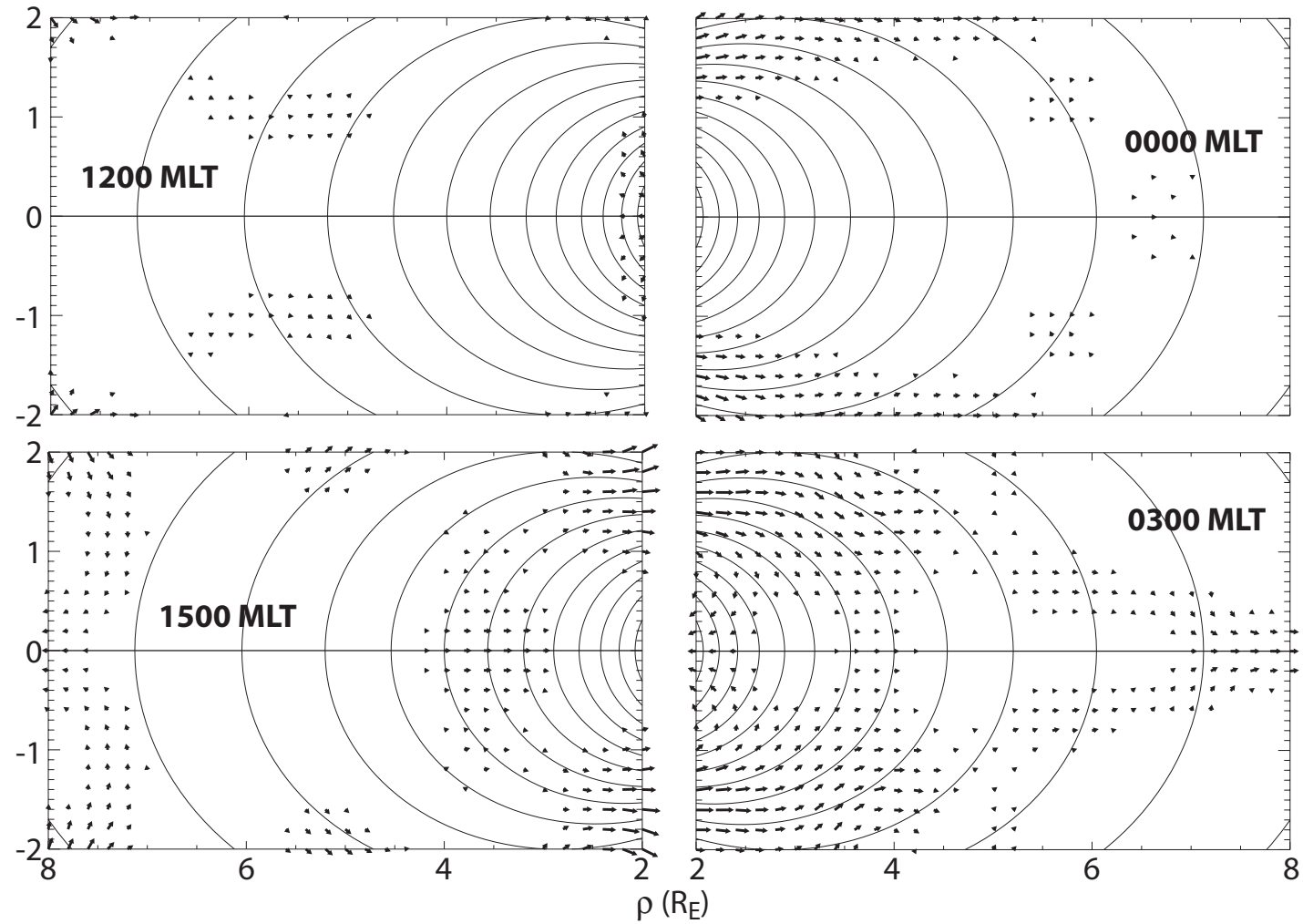

Fig. 10d. Meridional components of the current density as arrows in equally spaced grids in each of the 8 local time planes with superimposed dipole field lines for the four $D_{s t} *$ levels. The scale factor for the current density is different for different $D_{s t} *$ level. (d) $-80 \mathrm{nT}>D_{s t}{ }^{*}>-100 \mathrm{nT}$. 

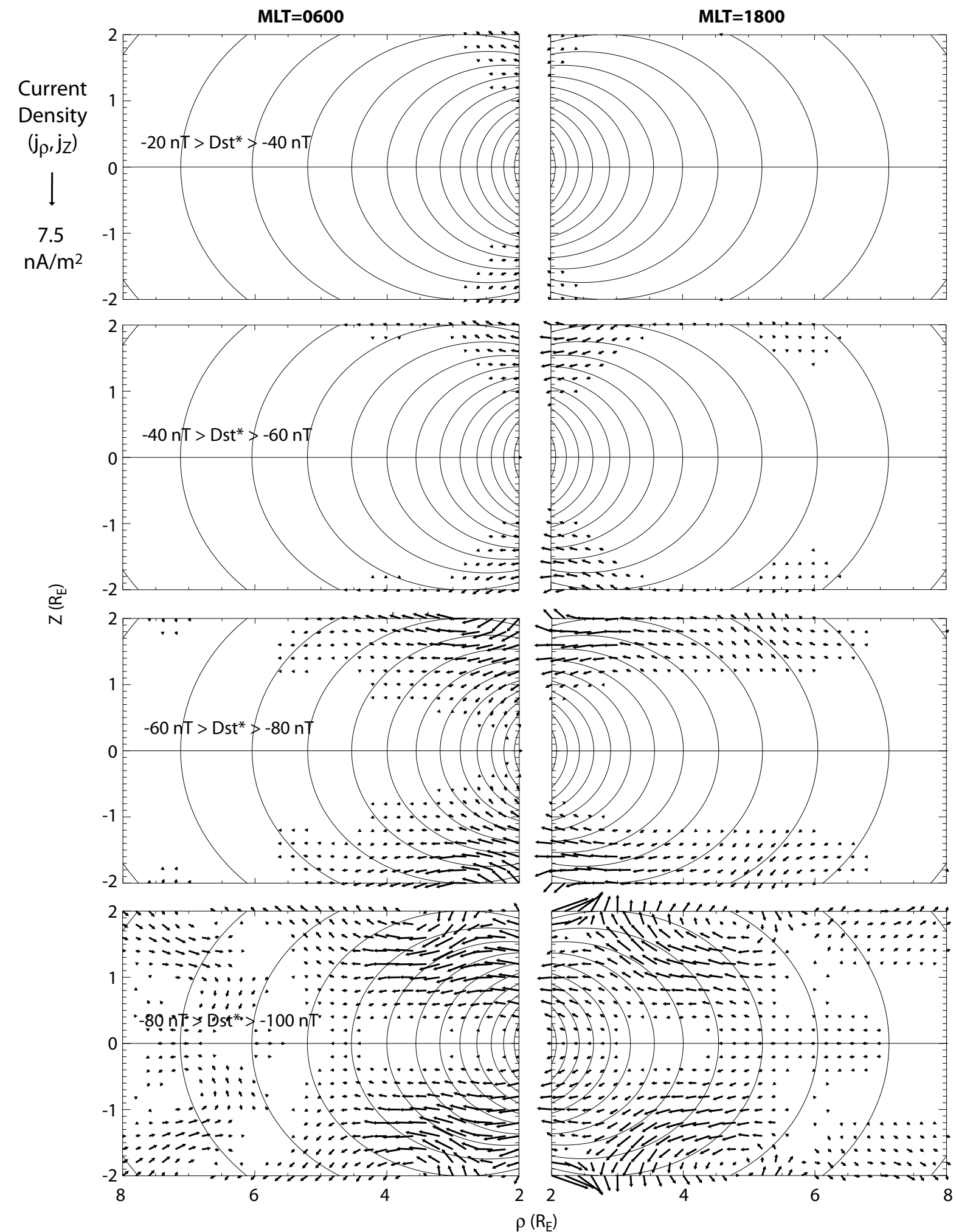

Fig. 11. Meridional components of the current density in the dawn-dusk meridian plane with a constant current vector scale for each of the $4 D_{s t} *$ levels superimposed on dipole field lines. 
is due to the inner pressure gradient of the ring current particles, and an outer westward current due to the outer pressure gradient of the ring current particles, plus their intrinsic drift in the Earth's magnetic field (e.g. Lui et al., 1987). We recall that the diamagnetic currents of the magnetospheric radiation belt cause a positive magnetic field at the center of the Earth (while locally depressing the field). The gradient and curvature drift of these same particles causes a negative downward magnetic field at the Earth's center.

The currents respond very much as we expect them to, as $D_{s t} *$ decreases. The azimuthal current system strengthens and the local time of the most intense ring current moves from post-midnight toward the dusk terminator. The unexpected result is that the ring current exhibits a strong daynight asymmetry for all disturbance levels. It is well known that the ring current is asymmetric during the storm main phase (Greenspan and Hamilton, 2000; Turner et al., 2001). Our results show that the ring current is always asymmetric, not just during the storm main phase. During quiet times, the symmetric ring current and the partial ring current are similar in strength, $\sim 0.5 \mathrm{MA}$. The partial ring current occurs in the nightside centered at midnight. As the level of geomagnetic disturbances increases, it is the partial ring current that shows the most drastic intensification and its peak moves towards dawn into the pre-midnight sector. Under moderate storm conditions $\left(-80 \mathrm{nT}>D_{s t} *>-100 \mathrm{nT}\right)$, the total partial ring current reaches a peak value of $\sim 2.6 \mathrm{MA}$, a factor of $\sim 5$ increase from its quiet-time value, whereas the total symmetric ring current remains well under $1 \mathrm{MA}$. Thus, some current clearly circles the magnetosphere (the symmetric ring current) but much of the energetic plasma stays in the night hemisphere as the partial ring current, which becomes dominant and contributes mainly to the decrease in the $D_{s t}$ index during magnetic storms.

The main carriers for the ring current are ions in the medium-energy range, $\sim 20-200 \mathrm{keV}$, and the mean energy is several tens of $\mathrm{keV}$ (see Williams, 1987 for a review). The time for a $50 \mathrm{keV}$ proton in the center of the ring current to drift completely around the Earth is several hours. Since the time for the build up of the ring current in the storm main phase is much more rapid than that, convection of the ring current particles, and not just the curvature/gradient drift, must be playing a substantial role for the intensification of the ring current. The convective transport of the plasmasheet plasma into the inner magnetosphere is driven by the enhanced convection electric field under a sustained period of southward IMF during the storm main phase. Conventionally, the partial ring current is thought to be carried by ions on open drift trajectories and the symmetric ring current by ions on closed drift trajectories. The striking feature of the dominant partial ring current in the nightside sectors indicates that the bulk of the ring current ions are not on closed trajectories during magnetic storms. Thus, the partial ring current ions that carry most of the energy flow into the inner magnetosphere, must be at sufficiently low energy that their motion is dominated by convection and not gradient drift. Since they do not appear to be readily convected to the dayside, it is possible that at lower L-values the convective transport to the dayside is not as readily possible as at higher auroral latitudes. Perhaps the dayside conducting ionosphere at low L-values forms a barrier to the convection and the low energy plasma builds on the nightside. In contrast, the plasma at auroral latitudes, where the lower electrical conductivity and the strong field-aligned current systems allow for fast convection to the dayside, has rapid transport from the nightside to the dayside and the reconnecting magnetopause. This suggestion is in accord with the work of Fok et al. (2003), who pointed out that different electric field models resulted in very different local time distribution for the ring current ions in modeling the stormtime ion drift trajectories. The classical picture where the partial ring current occurs in the afternoon sectors is associated with a strong electric field in the duskside, such as that in the Weimer electric field model (Weimer, 1995). When a strong stormtime electric field is present in the nightside, the partial ring current moves to nightside sectors and closes by region-2 field-aligned currents near dawn and dusk (Fok et al., 2001). However, our observations show nightside partial ring currents for all disturbances levels, not only in strong storms. Moreover, we do not see any evidence in our observations that the peak of the ring current ion flux moves to the post-midnight sector during storm intensifications, as predicted by this model. In contrast, the peak of the partial ring current moves towards the dusk terminator as the ring current intensifies in our observations. A recent statistical survey of plasma pressure distribution in the inner magnetosphere yields the same result (Lui, 2003).

The observed strong day-night asymmetry and the lack of significant partial ring current in the dayside afternoon sector argues against the details in most drift trajectory models that predict a morning-afternoon asymmetry due to a partial ring current in the afternoon sectors (Ejiri, 1978; Chen et al., 1993; Liemohn et al., 2001). Our results indicate that the partial ring current closes via meridional currents near dawn and dusk and not near noon and midnight. Thus, while the observations are telling a self-consistent story, the current models of the ring current plasma convection have yet to reproduce the observed global morphology of the ring current.

We do not believe that the strong day-night asymmetry reflects the loss processes of the ring current ions due to charge exchange and ion cyclotron pitch-angle scattering. The former process should be slightly stronger on the nightside than the dayside, because the hydrogen exosphere is slightly denser on the nightside (e.g. Bishop, 1985). We do not observe a significant day-night asymmetry in the ion cyclotron wave amplitude in the polar data (P. Chi, personal communication). Thus, asymmetry in the convective transport is the only remaining logical cause of the large local time asymmetry. The modeling work by Liemohn et al. $(1999,2001)$ suggested that convective drift loss of the ring current ions at the dayside magnetopause is the dominant loss process during the early recovery phase of magnetic storms. Both the observations in our study and this modeling work challenge the symmetric ring current paradigm, in which the ring current quickly becomes symmetric after the storm main phase, 
when the ions drifting on open drift trajectories are trapped in closed drift paths, in response to the decrease in the convection electric field, and subsequent losses are caused by the charge-exchange with exospheric neutrals, pitch-angle scattering into the loss cone by wave-particle interaction, as well as Coulomb drag energy loss (see reviews by Daglis et al., 1999; and Daglis and Kozyra, 2002). There is yet a weak symmetric component, presumably due to the higher energy particles that are less affected by the convective electric field.

In short, the ring current responds very much in space as we expect it would behave based on previous measurements of the plasma and magnetic field in the magnetosphere. However, one feature that was not well extracted from the groundbased data is that the ring current is very asymmetric in local time. During a storm period, reconnection on the dayside and in the tail both seem to be very strong and they pump up the energy content of the magnetosphere, but these energetic particles at low L-values appear not to be able to readily convect into the dayside magnetosphere.

Acknowledgements. The solar wind plasma data and $D_{s t}$ index used in this study are extracted from the Near-Earth Heliospheric data set (OMNI) available at the OMNIweb. The $D_{s t}$ index is calculated at Kyoto University. The work at UCLA was supported by the National Aeronautics and Space Administration under grant NAG5-11324. The work at JHU/APL was supported by the National Science Foundation under grants ATM-9901102 and ATM0000255.

Topical Editor P. Pulkkinen thanks N. Turner and T. Araki for their help in evaluating this paper.

\section{References}

Akasofu, S.-I., Polar and Magnetospheric Substorms, 44 pp., D. Reidel, Norwood, Mass., 1968.

Araki, T., Fumato, K., Iguchi, T., and Kamei, T.: Direct detection of solar wind dynamic pressure effect on ground magnetic field, Geophys. Res. Lett., 20, 775, 1993.

Bishop, J.: Geocoronal structure: The effects of solar radiation pressure and the plasmasphere interaction, J. Geophys. Res., 90, 5235-5245, 1985.

Burton, R. K., McPherron, R. L., and Russell, C. T.: An empirical relationship between interplanetary conditions and $D_{s t}$, J. Geophys. Res., 80 (31), 4204-4214, 1975.

Chapman, S. and Ferraro, V. C. A.: A new theory of magnetic storms, Terr. Mag., 36, 77-97, 1931.

Chapman S. and Ferraro, V. C. A.: The geomagnetic ring-current: I - its radial stability, Terr. Mag., 46, 1-6, 1941.

Chen, M. W., Schulz, M., Lyons, L. R., and Gorney, D. J.: Stormtime transport of ring current and radiation belt ions, J. Geophys. Res., 98, 3835-3849, 1993.

Daglis, I. A., and Kozyra, J. U.: Outstanding issues of ring current dynamics, J. Atmos. Solar-Terres. Phys., 64, 253-264, 2002.

Daglis, I. A., Thorne, R. M., Baumjohann, W., and Orsini, S.: The terrestrial ring current: Origin, formation, and decay, Rev. Geophys., 37, 407-438, 1999.

Dessler, A. J. and Parker, E. N.: Hydromagnetic theory of magnetic storms, J. Geophys. Res., 64, 2239-2259, 1959.

Ejiri, M.: Trajectory traces of charged particles in the magnetosphere, J. Geophys. Res., 83, 4798-4810, 1978.
Feldstein, Y. I.: Modelling of the magnetic field of magnetospheric ring current as a function of interplanetary medium parameters, Space Sci. Rev., 59, 83-165, 1992.

Fok, M.-C., Wolf, R. A., Spiro, R. W., and Moore, T. E.: Comprehensive computational model of the Earth's ring current, J. Geophys. Res., 106, 8417-8424, 2001.

Fok, M.-C., Moore, T. E., Wilson, G. R., Perez, J. D., Zhang, X. X., Son Brandt, P. C., Mitchell, D. G., Roelof, E. C., Jahn, J.-M., Pollock, C. J., and Wolf, R. A.: Global ENA Image Simulations, Space Sci. Rev., in press, 2003.

Greenspan, M. E. and Hamilton, D. C.: A test of the Dessler-ParkerSckopke relation during magnetic storms, J. Geophys. Res., 105, 5419-5430, 2000.

Hamilton, D. C., Gloeckler, G., Ipavich, F. M., Studemann, W., Wilken, B., and Kremser, G.: Ring current development during the great geomagnetic storm of February 1986, J. Geophys. Res., 93, 14343-14355, 1988.

Kamide, Y.: Relationship between substorms and storms, in: Dynamics of the Magnetosphere, Reidel, D. Publ. Co., Dordrecht, Holland, 425-443, 1979.

Le, G. and Russell, C. T.: Initial POLAR MFE observations of the low-altitude polar magnetosphere: Monitoring the ring current with polar orbiting spacecraft, J. Geophys. Res., 103, 17343, 1998.

Liemohn, M. W., Koyzra, J. U., Jordanova, V. K., Khazanov, G. V., Thomsen, M. F., and Cayton, T. E.: Analysis of early phase ring current recovery mechanisms during geomagnetic storms, Geophys. Res. Lett., 26, 2845-2848, 1999.

Liemohn, M. W., Koyzra, J. U., Thomsen, M. F., Roeder, J. L., Lu, G., Borovsky, J. E., and Cayton, T. E.: Dominant role of the asymmetric ring current in producing the stormtime $D_{s t}{ }^{*}, \mathrm{~J}$. Geophys. Res., 106, 10 883-10 094, 2001.

Lui, A. T. Y., McEntire, R. W., and Krimigis, S. M.: Evolution of the ring current during two geomagnetic storms, J. Geophys. Res., 92, 7459-7470, 1987.

Lui, A. T. Y.: Inner magnetospheric plasma pressure distribution and its local time asymmetry, Geophys. Res. Lett., 30, 16, 1846, doi:10.1029/2003GL017596, 2003.

Nakabe, S., Iyemori, T., Sugiura, M., and Slavin, J. A.: A statistical study of the magnetic field structure in the inner magnetosphere, J. Geophys. Res., 102, 17 571-17 582, 1997.

Petrinec, S. M. and Russel, C. T.: Near-Earth magnetotail shape and size as determined from the magnetopause flaring angle, J. Geophys. Res., 101, 137-152, 1996.

Potemra, T. A., Zanetti, L. J., and Acuña, M. H.: The AMPTE CCE Magnetic Field Experiment, IEEE Trans. Geosci. Remote Sensing, GE-23, 246-249, 1985.

Russell, C. T.: The ISEE 1 and 2 Fluxgate Magnetometers, IEEE Trans. Geosci. Remote Sensing, GE-16, 239-242, 1978.

Russell, C. T., McPherron, R. L., and Burton, R. K.: On the cause of geomagnetic storms, J. Geophys. Res., 79 (7), 1105-1109, 1974.

Russel, C. T., Ginskey, M., and Petrinec, S. M.: Sudden impulses at low-latitude stations: Steady state response for northward interplanetary magnetic field, J. Geophys. Res., 99, 253-261, 1994a.

Russel, C. T., Ginskey, M., and Petrinec, S. M.: Sudden impulses at low-latitude stations: Steady state response for southward interplanetary magnetic field, J. Geophys. Res., 99, 13 403-13 408, $1994 b$.

Russell, C. T., Snare, R. C., Means, J. D., Pierce, D., Dearborn, D., Larson, M., Barr, G., and Le, G.: The GGS/Polar magnetic fields investigation, Space Sci. Rev., 71, 563, 1995. 
Russell, C. T., Lu, G., and Luhmann, J. G.: Lessons from the ring current injection during the September 24-25 1998 storm, Geophys. Res. Lett., 27, 1371-1374, 2000.

Sckopke, N.: A general relation between the energy of trapped particles and the disturbance field near the Earth, J. Geophys. Res., 71, 3125, 1966.

Schmidt, A.: Erdmagnetismus, in: Enzyklopädie der Mathem. Wiss., VI, 265-396, 1917.

Störmer, C.: Sur les trajectories des corpuscales électrisés dans l'espace sous l'action du magnétisme terreste avec application aux aurores boreales, Arch. Sci. Phys. Nat. Geneve, 32, 117-123, 1911.

Singer, S. F.: A new model of magnetic storms and aurorae, Trans. AGU, 38, 175-190, 1957.

Turner, N. E., Baker, D. N., Pulkkinen, T. I., Roeder, J. L., Fennel, J. F., Jordanova, V. K.: Energy content in the storm time ring current, J. Geophys. Res., 106, 19 149-19 156, 2001.
Van Allen, J. A., Mcllwain, C. E., and Ludwig, G. H.: Radiation observations with satellite 1958a, J. Geophys. Res., 64, 271-286, 1959a.

Van Allen, J. A. and Frank, L. A.: Survey of radiation around the Earth to a radial distance of $107400 \mathrm{~km}$, Nature, 183, 430-434, $1959 b$.

Vernov, S. M., Gorchakov, E. V., Kuznetsov, S. N., Logachev, Y. I., Sosnovets, E. N., and Stolpovsky, V. G.: Particle fluxes in the outer geomagnetic field, Rev. Geophys., 7, 257-280, 1969.

Weimer, D. R.: Models of high-latitude electric potentials derived with a least error fit of spherical harmonic coefficients, J. Geophys. Res., 100, 19595-19607, 1995.

Williams, D. J.: Ring current and radiation belts, Rev. Geophys., 25, 570-578, 1987. 